\title{
Longitudinal Data on the Relations of Morphological and Phonological Training to Reading Acquisition in First Grade: The Case of Arabic Language
}

\author{
Reem Dallasheh-Khatib1, Raphiq Ibrahim ${ }^{1,2 *}$, Avi Karni1,2 \\ ${ }^{1}$ Department of Learning Disabilities, University of Haifa, Haifa, Israel \\ ${ }^{2}$ Edmond J. Safra Brain Research Center for the Study of Learning Disabilities, University of Haifa, Haifa, Israel \\ Email: ${ }^{*}$ raphiq@psy.haifa.ac.il
}

Received 9 March 2014; revised 8 April 2014; accepted 2 May 2014

Copyright @ 2014 by authors and Scientific Research Publishing Inc.

This work is licensed under the Creative Commons Attribution International License (CC BY).

http://creativecommons.org/licenses/by/4.0/

(c) (i) 0 pen Access

\section{Abstract}

The purpose of this study was to examine the development of morphological and phonological awareness and their impact on later reading skills. Two training programs (morphological and phonological awareness) were conducted in kindergarten and were compared to no-intervention control group. Phonological and morphological tests and other general abilities were measured for 90 children at kindergarten as pre and post intervention tests. Tests in reading and spelling were carried out at the middle of grade 1 . Results showed that the morphological and the phonological intervention programs enhanced both phonological and morphological awareness, in comparison to the control group, with a small advantage for the morphological group. In grade 1, no significant differences were found between the intervention groups and the control group in reading and spelling measures. Altogether the results of the current study suggest that the intervention programs were less effective than expected in the first graders compared to results of Carlisle (1995) and Lyster (2002), but support former findings found by Ibrahim et al. (2007). This result may relate in part to the additional visual complexity of Arabic orthography. The psycholinguistic implications of these findings including a gender effect are discussed.

\section{Keywords}

Reading Acquisition, Morphological Awareness, Phonological Awareness, Orthography, Kindergarten

\footnotetext{
${ }^{*}$ Corresponding author.
}

How to cite this paper: Dallasheh-Khatib, R., Ibrahim, R., \& Karni, A. (2014). Longitudinal Data on the Relations of Morphological and Phonological Training to Reading Acquisition in First Grade: The Case of Arabic Language. Psychology, 5, 918-940. http://dx.doi.org/10.4236/psych.2014.58103 


\section{Introduction}

For many years, the attempts to find the origin of reading impairments were based exclusively on reading research done in the English language and the main focus was on phonological awareness. It is widely known that there is a strong link between reading development and linguistic awareness (Bradley \& Bryant, 1983; Blachman, Ball, Black, \& Tangel, 1994; Brennan \& Ireson, 1997; Mann, 1998; Lundberg, 2009), and that the measures for phonological awareness taken prior to reading instruction predict later reading ability (Lyster, 2002). In contrast, little research has been conducted on the correlation between morphological abilities and reading. Nonetheless, a number of studies suggest that a causal connection between reading and morphology does exist (Arnbak \& Elbro, 2000; Brittain, 1970; Carlisle, 1987, 1995; Casalis, Colé, \& Sopo, 2004; Clin, Wade-Wooly, \& Heggie, 2009; Elbro \& Arnbak, 1996; Fischer, Shankweiler, \& Liberman, 1985; Fowler \& Liberman, 1995; Lyster, 2002; Nunes, Bryant, \& Bindman, 1997; Rubin, 1991; Torneus, 1987). Additionally, it has been argued that as the Arabic language, as well as Semitic languages in general, is "morphologically dense”, reading necessitates a strong background of morphological awareness even for the simplest of texts (Abu-Rabia, Share, \& Mansour, 2003; Berent \& Shimron, 1997; Deutsch, Frost, \& Forster, 1998; Geva, Wade-Woolley, \& Shany, 1997; Ibrahim, 2006). It is not clear whether and what degree insights that pertain to other languages can be applied to Arabic (such as English) as it is radically different in written form and orthography from Indo-European languages (Abu-Rabia et al., 2003). Furthermore, repeated investigations in English as well as in other languages support the notion that there are more factors contributing to the reading impairments (Landerl \& Wimmer, 2000).

This study was undertaken to examine the effect of intervention programs conducted in order to improve the phonological and morphological awareness in kindergarten children on their first grade reading abilities in Arabic as their first language.

\subsection{Characteristics of the Arabic Language}

Arabic distinguishes from other languages in its script, in a word sound and symbol repertoire, letter-to-sound congruency the relationships between spoken and written language (diglossia) (Ferguson, 1959) and letter-shape changes format along their positions (Ibrahim, 2009). Also, Arabic differ from most languages (Indo-European) in the reading direction, it is read from right to left. In the diglossic in Arabic, spoken dialect (Ammiya, also known as Spoken Arabic-SA) is used in daily life by all Arabs, and it doesn't have a written form. Literary Arabic (Fusha, and its current uses called Modern Standard Arabic-MSA) is used by educated people in literature, news (both written and oral) and intellectual conversations. To some extent, children entering the first grade who encounter literary Arabic for the first time can find it to be almost a foreign language (Abu-Rabia 2002; Abu-Rabia et al., 2003; Eviatar \& Ibrahim, 2001; Ibrahim \& Aharon-Peretz, 2005; Saiegh-Haddadd, 2003). Exposure to literary Arabic prior to the first grade assists children in learning how to read and write (Abu-Rabia, 2002), sharing a limited subgroup of words, the two forms of Arabic sematically, phonologically and syntactically are different. Related to this issue, the following background is pertinent: There is a semantic gap between SA and MSA. For example: the word "balcony" in English is برندة شرفة /baranda/ in SA while it is /shorfa/ in MSA. Therefore, a lexico/semantic representation of a spoken word might differ from its representation in the standard version although it is related to the same concept.

There is also phonological gap between SA and MSA. For example: the word dog “كلب" is pronounced as /kalb/ in the classical Arabic and /kalib/ in the spoken one (adding the phoneme /i/), or the word officer is pronounced as /dabet/ in the classical Arabic and /zabet/ in the spoken one (substituting the phoneme /d/ with /z/). Therefore, a specific phonological representation of a spoken word might differ from its phonological representation in the standard version although it is phonetically related to it (Saiegh-Haddad, 2004).

The Arabic language (Fusha) is composed of 29 letters. Its orthography is built on consonants and is read from right to left. The form of letter in Arabic changes according to its place within the word. Every letter can be made into four different forms: connected to the letter after it, connected to the letter before it, connected on both sides with other letters and not connected at all (for example, the phoneme /h/ is represented as: $4,+, \infty, \bullet$ ). The second characteristic has to do with diacritics and dots. In Arabic, many letters have a similar or even identical structure and are distinguished only on the basis of the existence, location and number of dots (e.g., the Arabic letters representing /t/(ت) and /n/ (ن) become the graphemes representing /th/ (ث) and /b/ (ب) by adding or changing the number or location of dots.

In the unvowelized form of the script, these letters can be disambiguated by their place in the word, as only 
word or syllable initial placement indicates the stop consonant. Almost one third of the words in Arabic are homographs, words that look similar to each other when written without vowelization, although they are pronounced differently and possess different meanings.

\subsection{The Arabic Morphology}

Arabic language is characterized by a nonconcatenative, highly productive derivational morphology. Most words are derived by embedding a root morpheme into a morphophonological word pattern. Most words are based on a trilateral root and various derivatives that are formed by the addition of affixes and vowels. The roots and phonological patterns are abstract entities and only their joint combination forms specific words. The core meaning is conveyed by the root, while the phonological pattern conveys word class information. For example, in Arabic the word (TAKREEM) consists of the root (KRM, whose semantic space includes things having to do with respect) and the phonological pattern TA_ _ EE_. The combination results in the word "honor".

A number of psycholinguistic studies have explored the effects of the morphology and orthography of other languages on lexical access and the structure of the mental lexicon (see in for example in Hebrew: Frost \& Bentin, 1992; Berent, 2002). These authors have suggested that the nonconcatenative and agglutinative morphological structure of Hebrew, together with the distributional properties of abstract word forms, results in the inclusion of subword morphological units in the mental lexicon of Hebrew speakers. Farid and Grainger (1996) suggested the same for the reading of Arabic. They showed that initial fixation position in a word results in somewhat different response patterns in French (which is similar to English in morphological structure and in reading direction) and in Arabic (which is similar to Hebrew in morphological structure and in reading direction). In French, fixation slightly to the left of the word's center results in best recognition for both prefixed and suffixed words, while in Arabic, prefixed words result in best recognition from leftward fixations and suffixed words result in best recognition from rightward initial fixations. They suggest that this is due to the greater importance of morphological structure in Arabic, because “... much of the phonological representation of the word can be recovered only after successfully matching the consonant cluster to a lexical representation” (p. 364), that is, after extraction of the root.

\subsection{Morphological Awareness}

When reading, many exceptional words according to a phonological perspective are regular words from a morphological perspective (Elbro \& Arnbak, 1996). Morphology refers to patterns of word configurations based on morphemes. Morphemes are the smallest possible units in language which possess meaning. Thus, the meaning of a word is, essentially, a combination of the meanings of the morphemes of a certain word (Arnbak \& Elbro, 2000; Elbro \& Arnbak, 1996). Morphological awareness is the ability to monitor and manipulate morphemes as distinct units in language usage. Morphological awareness is considered a part of metalinguistic skills (Casalis, Cole, \& Sopo, 2004; Clin, Wade-Woolley, \& Heggie, 2009).

Studies show that the mental lexicon of people is extremely sensitive to the morphology of language, especially in semetic languages as Arabic and Hebrew (Bentin \& Feldman, 1990; Berent \& Shimron, 1997; Deutsch et al., 1998; Eviatar \& Ibrahim, 2004; Ibrahim, 2006). This sensitivity can testify that decoding words relies on, at a hitherto unidentified stage, the morphological analysis of the written language. This analysis enhances and quickens the decoding process of the written language, and assists in the reading and spelling of numerous complex words (Arnbak \& Elbro, 2000).

A number of studies reported a positive correlation between good reading, spelling and the use of morphological connections in tasks concerning spoken and written language (Carlisle, 1987; Fischer et al., 1985; Wolter, Wood, \& D'zatko, 2009). Based on these studies, it appears that morphological analysis in reading is important to developing skills in reading and spelling. Additionally, morphological awareness of the spoken language is also important to reading in a manner similar to phonemic awareness (Arnbak \& Elbro, 2000).

Clin et al. (2009) sought in their research to explore how morphological awareness and prosodic sensitivity (stress and intonation patterns of a language) and the linguistic interaction between them (called also as morphophonology), develop and play a role in the reading ability of older elementary school children. Specifically, the research held two purposes. First, they wished to examine whether all derivational phonological changes are of equal difficulty for children, and second whether prosodic sensitivity and morphological awareness are significant predictors of reading ability. The researchers examined 1048 to 13 years old students, and measured 
children's ability to produce morphological derivations with differing levels of phonological complexity between stem and derivation: No change (e.g., appear-appearance), Phonemic change (e.g., elect-election), Stress change (e.g., human-humanity), and both phonemic and stress change (e.g., electric-electricity). Results showed that children perform significantly more poorly on both types of derivations that require stress changes than on phonemic change and no change derivations. Regression analyses showed that both prosodic sensitivity and morphological awareness are significant predictors of reading ability after controlling for age, verbal and nonverbal abilities, and phonological awareness. These results are true especially in derivations that require manipulation of stress, rather than manipulation of both stress and phonemic structure of the word. Probably since words that require both manipulations include frequent suffixes.

\subsection{Phonological Awareness}

Phonological awareness is a conscious approach to the phonetic level of speech and the cognitive ability to use representations at this level (Ball, 1993; Mann, 1998; Shany et al., 2001; Stanovich, 1986; Wagner \& Torgesen, 1987). Phonemes are small and abstract units of sounds of the language which cannot easily be separated from each other within the spoken word, as it is possible to separate syllables (Mann, 1998). Phonological awareness is one of the factors best predicting the ability of children to learn how to read (Ball, 1993; Mann, 1998; Stanovich, 1986; Wagner \& Torgesen, 1987). Additionally, the correlation between phonological awareness and reading development is extremely strong (Ball, 1993; Stanovich, 1986). Studies have shown clear evidence that individual differences in phonological awareness predict individual differences in reading in all languages so far studied (e.g., English, German, Swedish; Goswami, 2008). Furthermore, several studies found that training for phonological awareness assists in the development of reading (Blachman et al., 1994; Bradley \& Bryant, 1983, 1985; Brennan \& Ireson, 1997; Lundberg, 2009; Olfsson \& Lundbirg, 1983).

Lundberg (2009), in his article explores his longitudinal research training studies indicating the causal direction of the relation between phonological awareness and reading. He also reveals in his article a large and not yet fully completed and published intervention study. This study includes 1100 six years old students in preschool. A pre-training test was given in September of the last preschool year. Pre-test was followed by a long period of eight months training phonological awareness including games and exercises in group setting. After training a post test was given which was identical to the pre-test in order to explore the effect of the training period. Results show that phonological awareness is a highly modifiable ability, especially for girls (among the most highly performing found $73 \%$ girls and only $47 \%$ of the boys). SES also affected children's initial phonological awareness ability, since children coming from high SES schools clearly outperformed children coming from low SES school in the pre tests. It has been also found that the more a child gets training sessions, the more he gets a benefit of the training program.

Few studies have examined the both phonological and morphological awareness together. A longitudinal study from kindergarten to second grade examined the correlation between morphological analysis, phonological analysis and reading development in French (Casalis \& Louis-Alexandre, 2000). The tests were conducted during the three years of the research. In general, it appears that the performance of the children improved from kindergarten to first grade and from first grade to second grade in a majority of tests given. The correlations between phonological analysis and morphological analysis were extremely strong. This was particularly true in the correlation between syllabic deconstruction and the morphological tests in kindergarten, while the phonological deconstruction was strongly correlated with morphological tests in first and second grades. A robust correlation was also found between morphological analysis and reading. A regressive analysis showed that although phonological analysis played the largest part in explicating the differences in first grade, the two variables played the largest part in explaining the differences in reading and reading comprehension.

The study of Lyster (2002) compared the influence of training on phonological and morphological awareness in kindergarten aged children on reading development in first grade in Norwegian. The study had two training groups: morphological training and phonological training. In each, the children received training for thirty minutes per week for total period of 17 weeks. The control group had the usual curriculum for pre-school but was also visited from time to time by the researcher and exposed to the written word. The two test groups demonstrated improvement in phonological skills, morphological skills and reading in comparison to the control group. The effect of the training changed in relation to mother education: children from more educated mothers entered the intervention program with better meta-linguistic abilities than children of less educated mothers. Children from less educated mothers benefited more from the meta-morphological intervention program. However, nei- 
ther of the test groups did better than the other. Each one was better than the other in certain sub-groups. This pattern of results supports the theory that different meta-linguistic knowledge impacts differently the various stages of reading development (Tunmer \& Bowey, 1984). Additionally, it was found that a phonological foundation is required in order to develop morphological awareness, but development of morphological awareness can provide a means of compensating for phonological difficulties.

Although the importance of phonological and morphological awareness on reading acquisition is well supported, it is not clear whether these findings may equally apply to the Arabic language and its special condition of diglossia.

\subsubsection{The Current Research}

Owing to the importance of phonological and morphological abilities to reading development, and due to the complex morphological structure of the Arabic language, the current research examined the influence of training kindergarten children in phonological and morphological skills, separately, on their subsequent reading performance in first grade. The results of these intervention programs were compared to a no intervention control group. Although the training was conducted in literary Arabic an effort was made to use as many items as possible with as less linguistic distance as possible.

\subsubsection{Research Questions}

1) Would phonological training in the literary language enhance phonological awareness?

2) Would morphological training in kindergarten assist in advancing the morphological abilities of children?

3) Would one or both training programs help to improve reading abilities in the first grade in comparison to a no-intervention control group?

We assume that there would be a clear influence of the phonological and morphological training programs on the respective skills, such that children trained in phonological skills will attain higher scores on tests of phonological awareness than the control group, while the children trained in morphological skills will achieve higher scores in tasks of morphological awareness in comparison to the control group. Both these training programs would enhance reading ability in first grade.

\section{Method}

\subsection{Participants}

89 kindergarten children from a private school in Haifa were initially enrolled in this research. 31 from the one class participated in the phonological intervention program, 31 children who were in a different kindergarten class participated in the morphological intervention program, and 27 children from a third class had no intervention program and constituted the control group. Children in this kindergarten do not learn to read or write.

Seven children switched school, and hence were not included in the analysis: 2 children left the phonological group, 3 children left the morphological group, and 2 left the control group. The total number of the participants included in the statistical analysis was therefore 82; 29 from the phonological group, and 28 from the morphological group and 25 from the control group. The total number of females was 50 , and the total number of males was 32.

In Israel, all children are evaluated in kindergarten for emotional, learning, and attentional difficulties as part of a general screening for school readiness. None of the children in our samples suffered from known neurological, emotional, or attention disorders. Only children without a known developmental disability were tested.

\subsection{Research Design}

One of the authors and research assistants conducted both the pre and post tests and both of the intervention programs. Training for the research assistants included a presentation of background information on linguistic and meta-linguistic issues, reading development and the correlation between these variables. Additionally, all assistants learned to conduct both intervention programs. The assistants entered the intervention classes simultaneously and conducted the program for each class in mini-groups of 10 children on average, with one of the authors and assistants rotating between mini-groups. The reading tests in first grade were administered by one of the authors. 
There were two experimental groups and one no intervention control group: a Phonological intervention group, a Morphological intervention group, and a Control group which received no intervention of any kind, but continued the regular class curriculum. The children were allocated according to their placement in one of three given school classes. This procedure was chosen because we wanted to ensure uniformity as well as uniqueness in the learning experience afforded to each group of children. Children in the two intervention groups were exposed to print during the intervention. Intervention programs were conducted in the literary Arabic language, while trying to use as much items resembling the spoken Arabic language as possible. The training lasted for 8 weeks, and during each week each group received three sessions of 30 - 45 minutes each.

\subsubsection{The Phonological Training Group}

This group received training in phonological awareness. The training included the use of general sound recognition, rhymes, syllable and phoneme blending, segmenting. During the training, the children were exposed to letters and letter combinations which represent the sounds with which they are dealing. This intervention mode was based on the methods of Lyster (2002) (adapted to Arabic from English), and from Adams et al. (2001)_ adapted to Arabic from the Hebrew version). Exposure to print occurred during linguistic games which were built for the purposes of this research. Actually children saw the word/words included in the training set. For example, during a game of word identification with a rhyme or sound opening differently, they saw a group of target words on cardboard. Despite the exposure to the written word, direct instruction of grapheme-phoneme correspondence was not conducted.

\subsubsection{The Morphological Training Group}

This group was trained in morphological knowledge and morphological awareness. The group learned about the morphemes: أل- التعريف (corresponds to "the" in English), ألف الاثثين (morpheme used to derive singular to nouns or verbs to express “two"), and تاء التأنيث (the morpheme used to convert masculine words to feminine words), in nouns and verbs where possible. Each of these morphemes is an affix blended into the root morpheme or a derived word.

Children were trained with complex words, and a variety of the affixes mentioned above. The children learned to analyze and synthesize inflections and derivations, as well as to recognize the structure of morphological transformations and also learned the meaning added to a word after adding or removing these morphemes. Children of this group were also exposed to printed words but with no direct instruction of graphemephoneme correspondence.

\subsubsection{Control Group}

This group received no intervention whatsoever, but continued the usual class curriculum. The research assistants' visits to this group were only during the pre and post tests.

\subsection{Procedure}

The research was administered during two school years. During the first year, when children were in kindergarten, pre and post tests were administered aimed to explore the effect of training program in phonological and morphological awareness abilities in comparison to the control group. Also phonological and morphological intervention programs were administered during this year. A year after, when children were in the first grade, the reading tests were administered in order to explore the effects of each training program on reading in comparison to the no intervention control group.

Pre-tests were administered in kindergarten for the three experimental groups from the beginning of the second trimester of the school year. The intervention programs commenced at the beginning of the final trimester of the same school year. The post-tests were administered at the conclusion of the intervention programs. Reading tests were given to all three groups at the beginning of the second trimester of the school year in first grade. Each of the tests was administered to all groups at almost the same time. One of the authors and assistants administered the tests for the three groups simultaneously.

\subsection{Measures}

For purposes of this study, a set of tests to examine the effect of the interventions programs (pre and posttests) 
was constructed, as well as a set of reading tests for first grade in Arabic. Alpha Cronbach was computed from the test results of the current study.

\subsubsection{Pre and Post Measures}

Pre and post tests were administered in order to examine the effect of intervention programs on phonological and morphological awareness abilities in comparison with the control group.

Phonological awareness tests: these tests were designed for the purpose of the current study based on Lyster (2002).

1) Phonemes Count: The child heard 15 items in ascending order according to their level of difficulty. For each item, the child was asked to count the phonemes. While counting each phoneme, he/she was asked also to clap his/her hands or knock on the desk. Three examples were given prior to the actual test ( $\alpha=.767)$.

2) First phoneme match: The test included 12 items presented in ascending order, according to word size and linguistic distance from the spoken language. The child heard each item, after which he was asked to note which of three choice words shared a first phoneme with the target item. All of the items were similar to the target item in regards of word size and complexity. Pictures illustrating the items were shown to the children $(\alpha=.766)$.

3) Last phoneme match: A similar task to the first phoneme mach, in which the child was asked to match the target word with one of three words according to its last phoneme $(\alpha=.875)$. The task included 14 items.

Morphological tests: these tests were designed for the purpose of the current study based on Lyster (2002). In these tasks the child was asked to match between words conducted from the same root morpheme, one of which was simple, while the other was more complex. In the morphological analysis task the target word was complex, while the word to be chosen (i.e., the answer) was simple. In the other hand, the morphological synthesis task was the opposite: the target word was morphologically simple, and the target word was more complex.

1) Morphological analysis test: in this task the child was asked to choose one word of three, which matches a target word conducted from the same root. As mentioned above, the target word was morphologically complex, while the child needed to choose a word conducted from the same root, which was less complex. Words in this task were presented orally. This task included 15 items $(\alpha=.853)$.

2) Morphological synthesis test: this test was similar in construction to the previous one, except that the target word was a morphologically simple word, while the choice words were morphologically complex words. The child needs to choose the word conducted of the same root as the target word. This test too included 15 items which were presented orally $(\alpha=.888)$.

Each of the above tests was stopped after the child made three consecutive errors.

\subsubsection{General Abilities and Phonological Processing Tests}

1) Peabody Picture Vocabulary Test-Revised: A test examining vocabulary in which the child is told words and he must mark one out of four pictures. This test has no norms in Israel. The 50 first items of the test, translated into literary Arabic from the English version of the test (Dunn \& Dunn, 1981) were used on this research.

2) Verbal memory tests: Based on the Hebrew test of Shatil (2002) the test comprises 20 items. The child was requested to repeat meaningless syllabic constructions which vary from one to five syllables in length.

3) RAN Test (rapid automatized naming test): (based on the Denckla \& Rudel tests) (Denckla \& Rudel, 1976) the test is used to examine speed of processing. The test includes 5 objects which are randomly repeated ten times. The child is asked to name the objects with the highest possible speed. The performance of the child is measured in terms of naming time and accuracy.

4) Raven Standard Progressive Matrices (children's version): The test includes matrices with problems becoming progressively more difficult. The test is intended to examine a person's "inductive" ability (Zaaiman, Van der Filer, \& Thijs, 2001). The children's version includes three sets of 12 colorful items.

\subsection{Reading Tests}

A set of tests were constructed to examine reading ability. Performance was tested by scoring reading accuracy and speed. To reach independent tests of stimuli, two other language teachers were presented with the lists of words and evaluated them in terms of the extent to which variables such as frequency, number of letters, number of syllables, and morphological structure. Words that did not match the level of the grade were excluded. These same judges also rated the legality of the pseudo words on the lists. Reading tests were aimed to explore the ef- 
fect of the two intervention programs on reading development in comparison to the no intervention control group.

1) Words recognition test: The test included a column of pictures and across from it a column of words. The child was required to match the picture with the corresponding word. The test included 20 items $(\alpha=.646)$. The test was administered in a group manner, to each class separately.

2) Syllable reading: the child was asked to read 20 syllables presented on a single test page $(\alpha=.818)$. Syllables were of max 3 consonants.

3) Pseudo words reading: Included a list of 20 pseudo words $(\alpha=.835)$. Words in this test were conducted from one or two syllables. The syllables were part of the words that children usually learn in 1st grade.

4) Word reading: The material was selected to meet the most basic level of this grade and a pool of words was chosen from the formal books of the grade with the direct teachers (two 1st grade teachers who teach in other schools). Words were chosen so that part of them would be morphologically simple, including one syllable, like

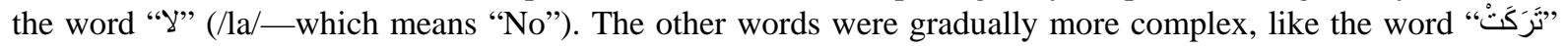
(/tarakat/, which means "she left"). Words were organized by frequency, as advised by the two teachers who evaluated the tests. This task included 42 words in which the child was required to read them all $(\alpha=.887)$.

5) Spelling: the choice of words was made at the same manner as the "Word Reading" test. This test was conducted in a group manner, for each class separately. The child was required to write 25 dictated words ( $\alpha$ $=.877)$.

\section{Results}

The results of the three test sessions, pre intervention, post-intervention interval (kindergarten), and the one year after $\left(1^{\text {st }}\right.$ grad $)$ are presented. Two new measures were derived: "combined phonological score" and "combined morphological score". The first measure (combined phonological score) was derived by simply adding the "first phoneme match" score to the "last phoneme score". The second measure was derived from adding "morphological analysis" score to "morphological synthesis" score. The reason lying behind these measures was that the two tests added in each measure rely on about the same factor (phonological awareness and morphological awareness, respectively) and both of them were tested in exactly the same manner.

\subsection{Kindergarten}

Table 1 summarized the descriptive statistics for the pre and post intervention tests that were conducted during the kindergarten phase of the study. A one way ANOVA was used to test the initial differences between the 3 study groups-phonological intervention (Phonological) group, morphological intervention (Morphological) group and control (no intervention) group, in pre test measures. The results showed that the initial performance on the verbal memory test $\left(\mathrm{F}_{(2,78)}=4.16, p<.05\right)$ was significantly different for the three groups. A post hoc test (Scheffe) showed a significant difference between the Phonological and the Morphological groups, with the Morphological group better $(p<.05)$ and a marginally significant difference between the morphological and the control groups with a somewhat better performance for the morphological group $(p=.074)$. Also, the initial performance of the three groups in the first phoneme match test was significantly different $\left(\mathrm{F}_{(2,79)}=4.04, p\right.$ $<.05$ ). A post hoc test (Scheffe) showed a marginally significant difference between the Phonological and the morphological groups $(p=.057)$, with better performance in the phonological group. Another initial difference was found in the combined phonological score $\left(\mathrm{F}_{(2,78)}=3.54, p<.05\right)$. A post hoc test (Scheffe) showed a significant difference between the Phonological and the Morphological groups $(p<.05)$, with better performance in the Phonological group. Finally, the initial performance of the three groups in the phoneme count test was also significantly different $\left(\mathrm{F}_{(2,79)}=4.04, p<.05\right)$. A post hoc test (Scheffe) showed a significant difference between the Phonological and the control groups $(p<.05)$, with better performance in the control group.

A second MANOVA was run to test the differences in performance in the three study groups, after the intervention interval, in the post tests. There were significant differences between the three study groups in some tests; these are shown in Table 2. Table 2 also presents the results of the post hoc tests (Scheffe). There was a significant difference in the performance of the three study groups in the phoneme count and verbal memory tests, tests in which differences between the groups were found even before the intervention period (i.e., in the pre-tests). However, after the intervention interval, the Morphological group showed a marginally significant difference from the control group in the first phoneme match test as well as a significant difference in the com- 
Table 1. Descriptive statistics for all tests in the pre and post testing sessions.

\begin{tabular}{|c|c|c|c|c|c|c|c|c|c|c|c|c|c|}
\hline \multirow[t]{2}{*}{ Test } & & \multicolumn{3}{|c|}{ Phonology } & \multicolumn{3}{|c|}{ Morphology } & \multicolumn{3}{|c|}{ Control } & \multicolumn{3}{|c|}{ Total } \\
\hline & & M & sd & $\mathrm{N}$ & M & sd & $\mathrm{N}$ & M & sd & $\mathrm{N}$ & M & sd & $\mathrm{N}$ \\
\hline \multirow{2}{*}{ Peabody } & Pre & 43.28 & 4.42 & 29 & 42.79 & 5.17 & 28 & 43.36 & 2.74 & 25 & 43.13 & 4.24 & 82 \\
\hline & Post & 45.67 & 3.29 & 27 & 45.07 & 2.96 & 28 & 45.33 & 2.35 & 24 & 45.35 & 2.89 & 79 \\
\hline \multirow{2}{*}{ Naming-time } & Pre & 88.75 & 22.65 & 29 & 93.96 & 21.31 & 28 & 88.73 & 26.7 & 24 & 90.55 & 23.32 & 81 \\
\hline & Post & 90.9 & 20.27 & 27 & 87.69 & 19.91 & 28 & 81.43 & 19.92 & 24 & 86.89 & 20.16 & 79 \\
\hline \multirow{2}{*}{$\begin{array}{l}\text { Naming-no' } \\
\text { of errors }\end{array}$} & Pre & .76 & 1.24 & 29 & 1.21 & 1.47 & 28 & .88 & 1.26 & 24 & .95 & 1.33 & 81 \\
\hline & Post & .81 & 1.39 & 27 & .46 & 1 & 28 & 1.71 & 1.55 & 24 & .96 & 1.4 & 79 \\
\hline \multirow{2}{*}{ Rhyme match } & Pre & 10.28 & 4.42 & 29 & 10.54 & 3.23 & 28 & 9.72 & 3.23 & 25 & 10.2 & 3.67 & 82 \\
\hline & Post & 11.67 & 3.4 & 27 & 11.29 & 3.2 & 28 & 10.58 & 3.4 & 24 & 11.2 & 3.31 & 79 \\
\hline \multirow{2}{*}{ Syllable count } & Pre & 8.69 & 2.82 & 29 & 7.54 & 3.32 & 28 & 6 & 4.18 & 25 & 7.48 & 3.58 & 82 \\
\hline & Post & 8.81 & 3.87 & 27 & 8.71 & 2.57 & 28 & 7.38 & 4.27 & 24 & 8.34 & 3.62 & 79 \\
\hline \multirow{2}{*}{ Phoneme count } & Pre & .38 & 1.01 & 29 & 1.04 & 1.86 & 28 & 1.64 & 1.91 & 25 & .99 & 1.69 & 82 \\
\hline & Post & 2.11 & 2.45 & 27 & .71 & 1.44 & 28 & 1.13 & 1.68 & 24 & 1.32 & 1.98 & 79 \\
\hline \multirow{2}{*}{$\begin{array}{l}\text { First phoneme } \\
\text { match }\end{array}$} & Pre & 7.55 & 3.56 & 29 & 5.36 & 3.25 & 28 & 5.96 & 3.37 & 25 & 6.32 & 3.49 & 82 \\
\hline & Post & 7.85 & 3.25 & 27 & 7.54 & 3.2 & 28 & 5.29 & 3.32 & 24 & 6.96 & 3.4 & 79 \\
\hline \multirow{2}{*}{$\begin{array}{l}\text { Last phoneme } \\
\text { match }\end{array}$} & Pre & 7.31 & 4.83 & 29 & 5 & 3.33 & 27 & 5.96 & 4.24 & 25 & 6.12 & 4.25 & 81 \\
\hline & Post & 9.78 & 3.66 & 27 & 9.21 & 4.32 & 28 & 6.75 & 4.52 & 24 & 8.66 & 4.32 & 79 \\
\hline \multirow{2}{*}{$\begin{array}{c}\text { Combined } \\
\text { phonology score }\end{array}$} & Pre & 15.23 & 6.37 & 26 & 10.41 & 5.53 & 27 & 12.17 & 6.66 & 24 & 12.58 & 6.43 & 77 \\
\hline & Post & 17.50 & 6.36 & 26 & 17.11 & 6.72 & 27 & 12.04 & 6.53 & 24 & 15.66 & 6.91 & 77 \\
\hline \multirow{2}{*}{ Spoonerism } & Pre & 0 & 0 & 29 & .14 & .52 & 28 & 0 & 0 & 25 & .05 & .31 & 82 \\
\hline & Post & .04 & .19 & 27 & .25 & 1.14 & 28 & .25 & 1.22 & 24 & .18 & .96 & 79 \\
\hline \multirow{2}{*}{$\begin{array}{l}\text { Morphological } \\
\text { analysis }\end{array}$} & Pre & 10.79 & 3.74 & 28 & 9.75 & 4.2 & 28 & 9.68 & 4.81 & 25 & 10.09 & 4.23 & 81 \\
\hline & Post & 11.45 & 4.34 & 29 & 11.46 & 4.03 & 28 & 10.04 & 4.47 & 24 & 11.04 & 4.27 & 81 \\
\hline \multirow{2}{*}{$\begin{array}{l}\text { Morphological } \\
\text { synthesis }\end{array}$} & Pre & 7.93 & 5.48 & 28 & 8.32 & 4.87 & 28 & 7.52 & 4.7 & 25 & 7.94 & 4.99 & 81 \\
\hline & Post & 11.04 & 4.43 & 27 & 11.18 & 4.47 & 28 & 7.75 & 5.38 & 24 & 10.09 & 4.94 & 79 \\
\hline \multirow{2}{*}{$\begin{array}{l}\text { COMBINED } \\
\text { morphology score }\end{array}$} & Pre & 18.48 & 8.19 & 25 & 18.07 & 8.22 & 28 & 17.88 & 7.54 & 24 & 18.14 & 7.90 & 77 \\
\hline & Post & 23.40 & 7.18 & 25 & 22.64 & 8.20 & 28 & 17.79 & 8.78 & 24 & 21.38 & 8.34 & 77 \\
\hline \multirow{2}{*}{ Verbal memory } & Pre & 10.41 & 2.32 & 29 & 12.07 & 2.45 & 27 & 10.56 & 2.27 & 25 & 11.01 & 2.44 & 81 \\
\hline & Post & 12.25 & 2.49 & 28 & 14.04 & 1.99 & 28 & 11.63 & 2.2 & 24 & 12.69 & 2.44 & 80 \\
\hline
\end{tabular}

bined phonology score, i.e., in the tests that were designed to examine phonological awareness abilities. The Phonological group also showed a marginally significant improvement in comparison to the control group, but in tests designed to measure morphological abilities, namely, the morphological synthesis test and in the combined morphological score.

In order to test the possible differential effects of the intervention programs, we compared the performance of the participants of the three study groups in the two kindergarten sessions (pre and post tests) for each of the tests, separately, using repeated measures ANOVAs. The results showed that all three groups improved in the 
Table 2. MANOVA results for the post intervention tests in which a significant group effect was found.

\begin{tabular}{|c|c|c|c|c|c|c|}
\hline Test & F value & df & Error df & $p$ & $\begin{array}{l}\text { Post hoc }{ }^{*} \\
\text { (scheffe) }\end{array}$ & $p$ for post hoc \\
\hline Phoneme count & 3.98 & 2 & 75 & $<.05$ & $\mathrm{p}>\mathrm{m}$ & $<.05$ \\
\hline First phoneme match & 4.42 & 2 & 75 & $<.05$ & $\begin{array}{l}\mathrm{p}>\mathrm{c} \\
\mathrm{m}>\mathrm{c}\end{array}$ & $\begin{array}{l}<.05 \\
=.054\end{array}$ \\
\hline Last phoneme match & 3.52 & 2 & 75 & $<.05$ & $\mathrm{p}>\mathrm{c}$ & $=.052$ \\
\hline Combined phonology score & 4.99 & 2 & 75 & $<.01$ & $\begin{array}{l}\mathrm{p}>\mathrm{c} \\
\mathrm{m}>\mathrm{c}\end{array}$ & $\begin{array}{l}<.05 \\
<.05\end{array}$ \\
\hline Morphological synthesis & 3.99 & 2 & 75 & $<.05$ & $\begin{array}{l}\mathrm{p}>\mathrm{c} \\
\mathrm{m}>\mathrm{c}\end{array}$ & $\begin{array}{l}=.073 \\
<.05\end{array}$ \\
\hline Combined morphology score & 3.28 & 2 & 75 & $<.05$ & $\mathrm{p}>\mathrm{c}$ & $=.076$ \\
\hline Naming-no' of errors & 5.9 & 2 & 75 & $<.01$ & $\begin{array}{l}\mathrm{p}<\mathrm{c} \\
\mathrm{m}<\mathrm{c}\end{array}$ & $\begin{array}{l}=.077 \\
<.01\end{array}$ \\
\hline Verbal memory & 8.42 & 2 & 75 & $<.001$ & $\begin{array}{l}\mathrm{m}>\mathrm{p} \\
\mathrm{m}>\mathrm{c}\end{array}$ & $\begin{array}{l}<.05 \\
<.001\end{array}$ \\
\hline
\end{tabular}

${ }^{*} \mathrm{p}=$ phonological group, $\mathrm{m}=$ morphological group, $\mathrm{c}=$ control group.

general ability tests, specifically in the Peabody, Raven and Verbal memory tests, although the improvement of the control group in the latter test was only marginally significant. In several tests only the two intervention groups, but not the control group, showed significant improvements across the intervention period. These tests included the morphological synthesis test, the combined morphology score, and the last phoneme match test (although the latter test showed only marginally significant improvement in the Phonological group). Only the Phonological group improved in the phoneme count test. However, the Morphological group improved in the morphological analysis, first phoneme match, combined phonology score, and there was also a significant improvement in the number of errors with a marginally significant improvement in the naming time in the naming test after the intervention compared to the pre test. The Control group showed significant improvement only in naming time. However, an analysis of the number of errors made, by the Control group, showed that there was a trade off between accuracy and fluency, since these participants had also increased the number of errors made in the post test. None of the study groups showed a significant improvement across the intervention period in the rhyme match, syllable count, and spoonerism tests (appendix 4, 5, 6). The results of each of the test in which significant learning effects were found (i.e., improvement from pre intervention to post intervention tests and scores) are presented in the following sub-sections a-h.

\section{a) Peabody}

All three study groups (Phonological, Morphological and Control) showed a significant improvement in the Peabody test. Comparisons of the three groups' performance at the two assessment time points was made using a 3 groups (Phonological, Morphological and Control; as between-subject factor) $\times 2$ time points (pre and post tests; as within-subject factor) ANOVA. There was a main effect for time-point $\left(\mathrm{F}_{(1,75)}=25.43, p<.001\right)$ with no significant interaction (groups $\times$ time-points) $\left(\mathrm{F}_{(2,75)}=.065, p=.937\right)$. A paired-samples t-test conducted for each group separately, showed significant improvement in all three groups: Phonological, Morphological and Control $\left(\mathrm{t}_{(25)}=-3.6, p=.001 ; \mathrm{t}_{(27)}=-2.54, p<.05 ; \mathrm{t}_{(23)}=-3.38, p<.01\right.$, respectively).

\section{b) Raven}

All the three study groups tested in the Raven test showed a significant improvement. Comparisons of the three groups' performance at the two assessment time points was made using a 3 group (Phonological, Morphological and Control, as between-subject factor) $\times 2$ time point (pre and post tests; as within-subject factor) ANOVA. There was a main effect for time-point $\left(\mathrm{F}_{(1,74)}=31.72, p<.001\right)$, but no significant interaction (groups $\times$ time-points $)\left(\mathrm{F}_{(2,74)}=.91, p=.41\right)$. A paired-samples t-test conducted for each group separately, showed significant improvements in all study groups: phonological, morphological and control groups $\left(\mathrm{t}_{(25)}=-2.77, p<.05\right.$; $\mathrm{t}_{(27)}=-2.53, p<.05 ; \mathrm{t}_{(23)}=-4.74, p<.001$, respectively).

\section{c) Verbal memory}

In all three study groups tested in the Verbal Memory test showed a significant improvement. Comparisons of 
the three groups' performance at the two assessment time points was made using a 3 groups (Phonological, Morphological and Control, as between-subject factor) $\times 2$ time points (pre and post tests; as within-subject factor) ANOVA. Results showed a main effect for time-point $\left(\mathrm{F}_{(1,75)}=27.36, p<.001\right)$ with no significant interaction (groups $\times$ time-points) $\left(\mathrm{F}_{(2,75)}=1.51, p=.23\right)$. There was significant main effect of group (between-subjects; $\left.\left[\mathrm{F}_{(2,75)}=7.99, p<.001\right]\right)$. Post hoc tests (Scheffe) showed that the participants of the Morphological group had a better performance than both the Phonological $(p<.005)$ and the Control $(p<.005)$ groups. A paired-samples t-test conducted for each group separately, showed significant improvements in Phonological and Morphological group $\left(\mathrm{t}_{(26)}=-2.83, p<.01 ; \mathrm{t}_{(26)}=-4.55, p<.001\right.$; respectively). The Control group showed only a marginally significant improvement $\left(\mathrm{t}_{(23)}=-1.98, p=.059\right)$.

\section{d) Morphological synthesis}

The two intervention groups tested in the morphological synthesis test showed a significant improvement in comparison to control group. Comparisons of the three groups' performance at the two assessment time points was made using a repeated measures ANOVA with 3 groups (Phonological, Morphological and Control) as between-subject factors $\times 2$ time points (pre and post tests) as within-subject factors. This analysis showed a main effect for time-point $\left(\mathrm{F}_{(1,74)}=12.26, p=.001\right)$ with a significant interaction (groups $\times$ time-points) $\left(\mathrm{F}_{(2,74)}=3.24\right.$, $p<.05)$. A paired-samples t-test conducted for each group separately, showed significant improvements for the Phonological and Morphological groups $\left(\mathrm{t}_{(24)}=-3.31, p<.01 ; \mathrm{t}_{(27)}=-3.01, p<.01\right.$, respectively). The control group, on the other hand, showed no significant improvement $\left(\mathrm{t}_{(23)}=.08, p=.94\right)$.

\section{e) Combined morphological score}

As the morphological analysis test and the morphological synthesis test rely on about the same factor, a combined measure of the two tests has been computed simply by adding the score of each test to the other (morphological analysis + morphological synthesis). The results of this score are presented in the following section.

The two intervention groups tested in the combined morphological score showed a significant improvement, while the control group showed no significant improvement. Comparisons of the three groups' performance at the two assessment time points was made using a 3 group (Phonological, Morphological and Control, as between-subject factor) $\times 2$ time point (pre and post tests; as within-subject factor) ANOVA. Results showed a main effect for time-point $\left(\mathrm{F}_{(1,74)}=14.33, p<.001\right)$ with a significant interaction (groups $\times$ time-points) $\left(\mathrm{F}_{(2,74)}=\right.$ 3.66, $p<.05)$. A paired-samples t-test conducted for each group separately, showed significant improvements for the Phonological and Morphological groups $\left(\mathrm{t}_{(24)}=-3.61, p=.001 ; \mathrm{t}_{(27)}=-3.01, p<.01\right.$, respectively). However, the Control group showed no significant improvement $\left(\mathrm{t}_{(23)}=.06, p=.95\right)$.

\section{f) Last phoneme match}

All the three study groups tested in the Last Phoneme Match test varied in there reaction to intervention. The Morphological group showed a significant improvement, the Phonological group showed marginally significant improvement, while the Control group showed no significant improvement at all. Comparisons of the three study groups' performance at the two assessment time points was made using a 3 group (Phonological, Morphological and Control, as between-subject factor) $\times 2$ time point (pre and post tests; as within-subject factor) ANOVA. The results demonstrated a main effect for time-point $\left(\mathrm{F}_{(1,74)}=16.99, p<.001\right)$ with a significant interaction (groups $\times$ time-points) $\left(\mathrm{F}_{(2,74)}=3.43, p<.05\right)$. There was marginally significant main effect of group (between-subjects; $\left[\mathrm{F}_{(2,74)}=2.94, p=.059\right]$ ) with the participants of the phonological group showing better performance than the control group $(p=.062)$.

A paired-samples t-test conducted for each of the study groups separately, showed significant improvements for the Morphological group $\left(\mathrm{t}_{(26)}=-5.94, p<.001\right)$. Moreover, a marginally significant improvement found in the Phonological group $\left(\mathrm{t}_{(25)}=-1.86, p=.075\right)$. While, The Control group showed no significant improvement $\left(\mathrm{t}_{(23)}=.6, p=.557\right)$.

\section{g) Phoneme count}

The results of phoneme count test performed prior to the intervention programs session showed a floor effect: $61 \%$ of the children could not correctly answer any of the items included in the test, while $26 \%$ could answer 1 or 2 items, and the rest (13\%) could answer only up to 8 items. The results of the post test showed a floor effect as well: $53.2 \%$ of the children couldn't answer any item, $29.1 \%$ could answer 1 or 2 items, and the rest (17.7\%) could answer only up to 9 items. Despite all, the Phonological group showed significant improvement in this test, as comparison to the other two study groups, the Morphological and the Control groups. Comparisons of the three groups' performance at the two assessment time points was made using a 3 group (Phonological, Morphological and Control, as between-subject factor) $\times 2$ time points (pre and post tests; as within-subject factor) 
ANOVA. Results showed no main effect for time-point $\left(\mathrm{F}_{(1,75)}=1.33, p=.25\right)$. However significant interaction was found (groups $\times$ time-points) found $\left(\mathrm{F}_{(2,75)}=8.81, p<.001\right.$.).

A paired-samples t-test conducted for each group separately, showed significant improvements in the Phonological group only $\left(\mathrm{t}_{(25)}=-3.98, p=.001\right)$. Morphological and Control groups showed no significant improvement $\left(\mathrm{t}_{(27)}=.83, p=.42 ; \mathrm{t}_{(23)}=1.24, p=.23\right.$ respectively).

\section{e) Morphological Analysis}

Only the Morphological group tested in the morphological analysis test showed a significant improvement as a comparison to the Phonological and the Control study groups. Comparisons of the three groups' performance at the two assessment time points was made using a 3 group (Phonological, Morphological and Control, as between-subject factor) $\times 2$ time point (pre and post tests; as within-subject factor) ANOVA. Results revealed a marginally significant main effect for time-point $\left(\mathrm{F}_{(1,76)}=3.01, p=.087\right.$ ) with no significant interaction (groups $\times$ time-points $)\left(\mathrm{F}_{(2,76)}=1.06, p=.35\right)$. A paired-samples t-test conducted for each group separately, showed significant improvements for the Morphological group only $\left(\mathrm{t}_{(27)}=-2.31, p<.05\right)$. The Phonological and the Control groups showed no significant improvement $\left(\mathrm{t}_{(26)}=-.82, p=.42 ; \mathrm{t}_{(23)}=0, p=1.0\right.$, respectively).

\section{f) First phoneme match}

Surprisingly, in all three groups tested in the first phoneme match task, only the Morphological group showed a significant improvement. That, in spite of the fact that this test was meant to measure phonological awareness abilities. Comparisons of the three groups' performance at the two assessment time points was made using a 3 group (Phonological, Morphological and Control, as between-subject factor) $\times 2$ time point (pre and post tests; as within-subject factor) ANOVA showed no effect for time-point $\left(\mathrm{F}_{(1,75)}=1.2, p=.28\right)$ with a significant interaction (groups $\times$ time-points) $\left(\mathrm{F}_{(2,75)}=31.61, p<.05\right)$. Moreover, there was a significant main effect of group (between-subjects; $\left[\mathrm{F}_{(2,75)}=3.91, p<.05\right]$ ). A post hoc test (Scheffe) showed that the participants of the Phonological group had a better performance than the Control group $(p<.05)$.

A paired-samples t-test conducted for each group separately, showed significant improvements for the Morphological group only $\left(\mathrm{t}_{(27)}=-4.34, p<.001\right)$. The Phonological and Control study groups showed no significant improvement $\left(\mathrm{t}_{(25)}=.04, p=.97, \mathrm{t}_{(23)}=.15, p=.26\right.$, respectively). Note that the analysis of the post tests displayed at the beginning of this section showed that there was no difference between the Phonological and the Morphological study groups. The reason for the significant improvement for the Morphological group, but not for the Phonological group, is that the initial point at the pre tests on the Morphological group (i.e., mean $=5.36$ ) was non significantly lower than the Phonological group (mean = 7.55). The improvement of the Morphological group after the intervention program leveled its performance to the Phonological group.

\section{g) Combined phoneme match score (first and last phoneme match)}

As the first and last phoneme match attempt to test the same ability (phonological awareness) at the same manner, a combined measure was computed for both of the tests.

In all three study groups tested in the combined phoneme match score there was a significant improvement only in the Morphological group. All together, between subject analyses proved that the Phonological study group has a better performance than the Control group. Comparisons of the three groups' performance at the two assessment time points was made using a 3 group (Phonological, Morphological and Control, as between-subject factor) $\times 2$ time point (pre and post tests; as within-subject factor) ANOVA showed a main effect for time-point $\left(\mathrm{F}_{(1,74)}=11.77, p=.001\right)$ with a significant interaction (groups $\times$ time-points) $\left(\mathrm{F}_{(2,74)}=5.44, p<.01\right)$. There was significant main effect of group (between-subjects; $\left[\mathrm{F}_{(2,74)}=4.41, p<.05\right]$ ). Post hoc test (Scheffe) demonstrated that the participants of the Phonological group showing better performance than the Control group $(p<.05)$.

A paired-samples t-test conducted for each group separately, showed significant improvements for the Morphological group only $\left(\mathrm{t}_{(26)}=-7.06, p<.001\right)$. The Phonological and the Control group showed no improvement $\left(\mathrm{t}_{(26)}=-1.21, p=.24 ; \mathrm{t}_{(23)}=.08, p=.94\right)$.

\section{h) Naming}

\subsubsection{Naming Time}

The groups tested in the naming time test showed a significant improvement in the Control and Morphological group only. Comparisons of the three groups' performance at the two assessment time points was made using a 3 group (Phonological, Morphological and Control, as between-subject factor) $\times 2$ time point (pre and post tests; as within-subject factor) ANOVA showed a main effect for time-point $\left(\mathrm{F}_{(1,74)}=4.6, p<.05\right)$ with a marginally significant interaction (groups $\times$ time-points) $\left(\mathrm{F}_{(2,74)}=3.02, p=.055\right)$. A paired-samples t-test conducted for 
each group separately, showed a marginally significant improvement in Morphological group and a significant effect in the Control group $\left(\mathrm{t}_{(27)}=-2.01, p=.055 ; \mathrm{t}_{(23)}=2.33, p<.05\right.$, respectively). The Phonological group showed no improvement. In contrast, they have declined as there reaction time in the naming test got higher $\left(\mathrm{t}_{(25)}\right.$ $=-.79, p=.44$ ).

\subsubsection{Number of Errors}

The groups tested showed significant improvement in the Morphological group. The Control group demonstrated a significant decline, while the Phonological group showed no significant change. Comparisons of the three groups’ performance at the two assessment time points was made using a 3 group (Phonological, Morphological and Control, as between-subject factor) $\times 2$ time point (pre and post tests; as within-subject factor) ANOVA showed no main effect for time-point $\left(\mathrm{F}_{(1,74)}=.001, p=.97\right)$ with a significant interaction (groups $\times$ time-points) $\left(\mathrm{F}_{(2,74)}=4.19, p<.05\right)$. A paired-samples t-test conducted for each group separately, showed significant improvements in Morphological group $\left(\mathrm{t}_{(27)}=2.26, p<.05\right)$. The Control group showed an increase of the average number of errors $\left(\mathrm{t}_{(23)}=2.33, p<.05\right)$. The Phonological group showed no improvement $\left(\mathrm{t}_{(25)}=-.21, p=.84\right)$.

Looking at the accuracy (number of errors) and fluency (time measure) together demonstrate the overall behavior of the three groups. Namely, the Control group got faster yet more impulsive-did more errors. The Phonological group did not change over time, while the Morphological group improved significantly, in their reaction time and the number of the errors made.

\subsubsection{Reading Tests in $1^{\text {st }}$ Grade}

Table 3 summarizes the descriptive statistics for the reading tests administered in the first grade for all three groups. The results are presented for each group, separately.

To test for differences between the three study groups in reading abilities ANOVA tests were run for each of the reading tests separately. As opposed to assumptions, there were no significant differences between the study groups in the performance of any of the tests that were administered to measure reading abilities. However, when the reading tests' results were re-analyzed, taking gender into account, significant gender differences were found in two reading tests: pseudo word reading fluency and spelling test. Moreover, in the pseudo word reading fluency measure, males showed a marginally significant improvement in the phonological and the morphological groups, but not in the control group. These effects were not found for females. A gender effect was also found in the spelling test, with a significant effect for groups, in the males, but not in females. The results of the above two tests are presented below. The results of the analysis of the other reading tests (in which no significant differences were found between groups) are presented in appendix 8.

\subsection{Pseudo Word Reading}

For pseudo word reading accuracy, across both genders, a univariate analysis of variance showed no main effect for group $\left(\mathrm{F}_{(2,77)}=.89, p=.42\right)$. Similarly, for fluency, a univariate analysis of variance showed no main effect for group $\left(\mathrm{F}_{(2,77)}=1.12, p=.33\right)$. However, a somewhat different pattern of results emerged when the data was analyzed taking gender into account. For accuracy, an ANOVA with 3 groups (Phonological, Morphological and Control $) \times 2$ genders showed no main effect for group $\left(\mathrm{F}_{(2,74)}=.95, p=.39\right)$ and gender $\left(\mathrm{F}_{(1,75)}=.2, p=.66\right)$ and no significant interaction $\left(\mathrm{F}_{(2,74)}=.55, p=.58\right)$. However, a corresponding ANOVA for fluency, showed no main effect for group $\left(\mathrm{F}_{(2,74)}=1.96, p=.15\right)$, or for gender $\left(\mathrm{F}_{(1,74)}=.27, p=.61\right)$ but, a significant interaction was found $\left(\mathrm{F}_{(2,74)}=3.32, p<.05\right)$. An independent-samples t-test conducted for each group separately, showed no significant differences between groups-phonology $\left(\mathrm{t}_{(26)}=-1.04, p=.31\right)$, morphology $\left(\mathrm{t}_{(26)}=-.67, p=.51\right)$, Control $\left(\mathrm{t}_{(22)}=1.82, p=.094\right)$. Note that, females seem to be slower in the Phonological and the Morphological groups, but faster in the Control group. This might explain the interaction effect found. Because of this, a univariate analysis of variance was run for each gender separately. Those results show a significant group effect for males $\left(\mathrm{F}_{(2,29)}=3.37, p<.05\right)$, but not for females $\left(\mathrm{F}_{(2,46)}=.16, p=.85\right)$. A Post Hoc test (Scheffe) for the male group showed only a marginally significant difference between the phonological group $(\mathrm{M}=150.72$ secs., $\mathrm{sd}=$ $72.3, p=.064)$ and the control group $(M=257.29$ secs., $s d=146.27)$. Also, a similar marginally significant effect was found between the morphological group $(M=153.54$, $s d=84.89)$ and the control group $(M=257.29$ secs., sd $=146.27, p=.092$ ). No such differences were found in the post hoc tests (Scheffe) for the female group. 
Table 3. Descriptive statistics computed for reading tests in $1^{\text {st }}$ grade.

\begin{tabular}{cccccccccccccc}
\hline & \multicolumn{1}{c}{ Phonology } & \multicolumn{3}{c}{ Morphology } & \multicolumn{3}{c}{ Control } & \multicolumn{3}{c}{ Total } \\
\hline Test & M & sd & N & M & sd & N & M & sd & N & M & sd & N \\
Word recognition & 18.39 & 1.87 & 28 & 19.18 & 1.63 & 28 & 19.33 & .97 & 21 & 18.94 & 1.62 & 77 \\
Syllable reading & 15.82 & 2.28 & 28 & 16.14 & 3.62 & 28 & 14.86 & 3.86 & 21 & 15.68 & 3.27 & 77 \\
Syllable reading time & 115.34 & 74.34 & 28 & 125.85 & 78.65 & 28 & 131.42 & 84.94 & 21 & 123.55 & 78.12 & 77 \\
Pseudo word reading & 13.00 & 4.39 & 28 & 14.11 & 4.18 & 28 & 12.71 & 3.77 & 21 & 13.32 & 4.14 & 77 \\
Pseudo word reading time & 172.21 & 81.77 & 28 & 167.92 & 90.28 & 28 & 199.18 & 88.76 & 21 & 178.00 & 86.71 & 77 \\
Word reading & 25.18 & 7.87 & 28 & 27.64 & 7.58 & 28 & 23.57 & 7.49 & 21 & 25.64 & 7.74 & 77 \\
Word reading time & 426.44 & 229.33 & 28 & 432.48 & 234.26 & 28 & 488.47 & 295.03 & 21 & 445.55 & 248.58 & 77 \\
Word spelling & 16.57 & 4.82 & 28 & 18.64 & 5.11 & 28 & 18.24 & 5.41 & 21 & 17.78 & 5.11 & 77 \\
\hline
\end{tabular}

\subsection{Spelling}

Univariate analysis of variance showed no main effect for group $\left(\mathrm{F}_{(2,77)}=1.13, p=.33\right)$. An ANOVA test 3 (groups-Phonological, Morphological and Control) $\times 2$ (gender) found no main effect for group $\left(\mathrm{F}_{(2,74)}=1.89\right.$, $p=.16)$, for gender $\left(\mathrm{F}_{(1,74)}=1.87, p=.18\right)$. But, a significant interaction was found $\left(\mathrm{F}_{(2,74)}=3.25, p<.05\right)$. An independent-samples t-test conducted for each study group separately, showed no significant differences between test groups-Phonology $\left(\mathrm{t}_{(26)}=-1.3, p=.2\right)$, Morphology $\left(\mathrm{t}_{(26)}=1.22, p=.23\right)$. But the Control group showed a significant difference $\left(\mathrm{t}_{(22)}=-2.11, p<.05\right)$ between males $(\mathrm{M}=14.89$, sd $=6.58)$ and females $(\mathrm{M}=$ 19.6, sd $=4.37$ ). A univariate analysis was run to test difference between groups for each gender separately. Moreover, it has been found a marginally significant main effect for group when dealing with males $\left(\mathrm{F}_{(2,28)}=\right.$ $3.16, p=.058)$ but not for females $\left(\mathrm{F}_{(2,47)}=.91, p=.41\right)$. A post hoc test for males found no significant differences between groups.

\subsection{Correlation Analyses}

In order to study the relationship between the performance in the pre-test battery and the participants' reading abilities, the correlations between performance measures in the various tests in the pre-test and the reading test measures were computed. Table 4 shows the Pearson's correlations between pre tests measured in kindergarten and the reading tests measured in $1^{\text {st }}$ grade. As can be seen, none of the pre tests correlated significantly with word recognition test. We exclude the verbal memory test that correlated with this test in a low significance and correlation $(r=.230, p<.05)$. However, the tests first phoneme match and combined morphology score matched with most of the reading tests. Namely, the tests of syllable reading fluency, pseudo word reading accuracy, pseudo word reading fluency, word reading accuracy, word reading fluency, and spelling. Those test were correlated with reading tests in a range of .321 - .374 (absolute value) in the first phoneme match, and .313 - .436 (absolute value) in the combined morphology score. Other tests also correlated with reading tests, but with lower correlations and/or lower significance.

A similar correlation analysis was performed to study the relationship between the performance in the post-test that took place in kindergarten, and the reading tests admitted in the $1^{\text {st }}$ grade. As seen in this Table 5, the performance levels in the tests rhyme match, first phoneme match, last phoneme match, and morphological synthesis were significantly correlated with all of the reading tests. The correlations in those tests varied from .224 - .455 (absolute value), all in high significance. Most of the other post tests correlated with part of reading tests too.

Pearson correlations between the different reading tests are presented in Table 6. Those results show that all the reading tests correlated with each other with a high level of significance, except for the word recognition test. This suggests that word recognition test might examine things that are beyond merely reading abilities. It could, for example, test visual perception ability, or anything regarding the visual-spatial abilities. 
Table 4. Pearson correlations between pre tests admitted in kindergarten and reading tests admitted in the $1^{\text {st }}$ grade.

\begin{tabular}{|c|c|c|c|c|c|c|c|c|}
\hline & $\begin{array}{l}\text { Word } \\
\text { recognition }\end{array}$ & $\begin{array}{l}\text { Syllable } \\
\text { reading }\end{array}$ & $\begin{array}{l}\text { Syllable } \\
\text { reading time }\end{array}$ & $\begin{array}{l}\text { Pseudo } \\
\text { reading }\end{array}$ & $\begin{array}{l}\text { Pseudo } \\
\text { reading time }\end{array}$ & Word reading & $\begin{array}{l}\text { Words } \\
\text { reading time }\end{array}$ & Spelling \\
\hline Pre naming time & .06 & -.205 & $.228\left(^{*}\right)$ & -.042 & .093 & -.063 & .194 & -.091 \\
\hline Pre naming errors & .119 & -.026 & -.004 & -.069 & -.021 & -.109 & -.021 & .03 \\
\hline Pre verbal memory & $.230\left(^{*}\right)$ & .166 & $-.302\left(^{* *}\right)$ & $.266\left(^{*}\right)$ & $-.373\left(^{* *}\right)$ & $.268\left(^{*}\right)$ & $-.419\left(^{* *}\right)$ & $.275\left(^{*}\right)$ \\
\hline Pre peabody & -.051 & .179 & $-.222\left(^{*}\right)$ & .176 & -.157 & .183 & $-.250\left(^{*}\right)$ & $.257\left(^{*}\right)$ \\
\hline Pre raven & -.21 & $.261\left(^{*}\right)$ & $-.219\left(^{*}\right)$ & .196 & $-.257\left(^{*}\right)$ & .147 & $-.220\left({ }^{*}\right)$ & .168 \\
\hline Pre rhyme match & .055 & $.220\left(^{*}\right)$ & $-.331\left(^{* *}\right)$ & .217 & $-.308\left(^{* *}\right)$ & $.232\left({ }^{*}\right)$ & $-.377\left(^{* *}\right)$ & $.416\left(^{* *}\right)$ \\
\hline Pre syllable count & .026 & .087 & $-.229\left(^{*}\right)$ & .079 & -.147 & .04 & -.199 & .103 \\
\hline Pre phoneme count & .204 & -.065 & -.137 & .018 & -.163 & -.076 & -.14 & .184 \\
\hline $\begin{array}{l}\text { Pre first phoneme } \\
\text { match }\end{array}$ & .075 & $.273\left(^{*}\right)$ & $-.374\left(^{* *}\right)$ & $.344\left(^{* *}\right)$ & $-.346\left(^{* *}\right)$ & $.321\left(^{* *}\right)$ & $-.357\left(^{* *}\right)$ & $.342\left(^{* *}\right)$ \\
\hline $\begin{array}{l}\text { Pre last phoneme } \\
\text { match }\end{array}$ & .048 & .195 & $-.324\left(^{* *}\right)$ & .149 & $-.280\left(^{*}\right)$ & .15 & $-.280\left(^{*}\right)$ & .163 \\
\hline $\begin{array}{l}\text { Pre combined } \\
\text { phonology }\end{array}$ & .066 & $.273\left(^{*}\right)$ & $-.410\left(^{* *}\right)$ & $.281\left(\left(^{*}\right)\right.$ & $-.370\left(^{* *}\right)$ & $.277\left({ }^{*}\right)$ & $-.376\left(^{* *}\right)$ & $.286\left({ }^{*}\right)$ \\
\hline Pre spoonerism & .106 & .11 & -.149 & .171 & -.164 & .203 & -.147 & .211 \\
\hline $\begin{array}{c}\text { Pre morphological } \\
\text { analysis }\end{array}$ & .128 & $.332\left({ }^{* *}\right)$ & $-.373\left(^{* *}\right)$ & $.364\left(^{* *}\right)$ & $-.326\left(^{* *}\right)$ & $.297\left(^{* *}\right)$ & $-.400\left(^{* *}\right)$ & $.363\left(^{* *}\right)$ \\
\hline $\begin{array}{c}\text { Pre morphological } \\
\text { synthesis }\end{array}$ & .034 & .145 & $-.351\left(^{* *}\right)$ & $.248\left(^{*}\right)$ & $-.371\left(^{* * *}\right)$ & $.255\left(^{*}\right)$ & $-.366\left(^{* *}\right)$ & $.318\left(^{* *}\right)$ \\
\hline $\begin{array}{c}\text { Pre combined } \\
\text { morphology }\end{array}$ & .089 & $.264\left(^{*}\right)$ & $-.413\left(^{* *}\right)$ & $.346\left(^{* *}\right)$ & $-.403\left({ }^{* *}\right)$ & $.313\left(\left(^{* *}\right)\right.$ & $-.436\left(^{* *}\right)$ & $.388\left(^{* *}\right)$ \\
\hline
\end{tabular}

${ }^{* *}$ Correlation is significant at the .01 level (2-tailed). ${ }^{*}$ Correlation is significant at the .05 level (2-tailed).

Table 5. Pearson correlations between post tests admitted in kindergarten and reading tests admitted in $1^{\text {st }}$ grade.

\begin{tabular}{|c|c|c|c|c|c|c|c|c|}
\hline & $\begin{array}{l}\text { Word } \\
\text { recognition }\end{array}$ & $\begin{array}{l}\text { Syllable } \\
\text { reading }\end{array}$ & $\begin{array}{l}\text { Syllable } \\
\text { reading time }\end{array}$ & $\begin{array}{l}\text { Pseudo word } \\
\text { reading }\end{array}$ & $\begin{array}{l}\text { Pseudo word } \\
\text { reading time }\end{array}$ & $\begin{array}{l}\text { Word } \\
\text { reading }\end{array}$ & $\begin{array}{l}\text { Word reading } \\
\text { time }\end{array}$ & Spelling \\
\hline Post naming time & -.032 & -.205 & $.269\left({ }^{*}\right)$ & -.154 & .159 & -.086 & $.236\left({ }^{*}\right)$ & $-.235\left(^{*}\right)$ \\
\hline Post naming errors & .119 & $-.250\left(^{*}\right)$ & .133 & -.121 & .164 & -.181 & -.026 & -.139 \\
\hline Post verbal memory & .091 & $.310\left(^{* *}\right)$ & $-.356\left(^{* *}\right)$ & $.321\left(^{* *}\right)$ & $-.391\left(^{* *}\right)$ & $.308\left(^{* *}\right)$ & $-.382\left(^{* *}\right)$ & $.272\left({ }^{*}\right)$ \\
\hline Post peabody & .16 & .189 & $-.258\left(^{*}\right)$ & .177 & -.195 & .17 & $-.251\left(^{*}\right)$ & $.271\left(^{*}\right)$ \\
\hline Post rhyme match & $.275\left(^{*}\right)$ & $.224\left(^{*}\right)$ & $-.322\left(^{* *}\right)$ & $.295\left(^{* *}\right)$ & $-.345{\left({ }^{* *}\right)}^{*}$ & $.249\left(^{*}\right)$ & $-.365\left(^{* *}\right)$ & $.386\left(^{* *}\right)$ \\
\hline Post syllable count & .134 & $.246\left(^{*}\right)$ & -.155 & $.242\left({ }^{*}\right)$ & -.202 & .145 & $-.237\left(^{*}\right)$ & $.273\left(^{*}\right)$ \\
\hline Post phoneme count & .083 & .095 & $-.230\left(^{*}\right)$ & .148 & -.186 & .111 & -.205 & .059 \\
\hline $\begin{array}{l}\text { Post first phoneme } \\
\text { match }\end{array}$ & $.372\left(^{* *}\right)$ & $.360\left(^{* *}\right)$ & $-.433\left(^{* *}\right)$ & $.455\left(^{* *}\right)$ & $-.475\left(^{* *}\right)$ & $.390\left(^{* * *}\right)$ & $-.445\left(^{* *}\right)$ & $.401\left(^{* *}\right)$ \\
\hline $\begin{array}{l}\text { Post last phoneme } \\
\text { match }\end{array}$ & $.318\left(^{* *}\right)$ & $.419\left(^{* *}\right)$ & $-.372\left(^{* *}\right)$ & $.395\left(^{* *}\right)$ & $-.368\left(^{* *}\right)$ & $.308\left(^{* *}\right)$ & $-.336\left(^{* *}\right)$ & $.383\left({ }^{* *}\right)$ \\
\hline $\begin{array}{l}\text { Post combined } \\
\text { phonology }\end{array}$ & $.379\left(^{* *}\right)$ & $.439\left(^{* *}\right)$ & $-.445\left(^{* *}\right)$ & $.470\left(^{* *}\right)$ & $-.462\left(^{* *}\right)$ & $.382\left(^{* *}\right)$ & $-.426\left(^{* *}\right)$ & $.436\left(^{* *}\right)$ \\
\hline Post spoonerism & .078 & .157 & -.175 & .202 & -.152 & .213 & -.177 & .184 \\
\hline $\begin{array}{l}\text { Post morphological } \\
\text { analysis }\end{array}$ & .176 & $.306\left(^{* *}\right)$ & $-.284\left(^{*}\right)$ & $.362\left(^{* *}\right)$ & $-.262\left(^{*}\right)$ & $.323\left(^{* *}\right)$ & $-.240\left(^{*}\right)$ & $.418\left(^{* *}\right)$ \\
\hline $\begin{array}{l}\text { Post morphological } \\
\text { synthesis }\end{array}$ & .273()$\left.^{*}\right)$ & $.389\left(^{* *}\right)$ & $-.404\left(^{* *}\right)$ & $.338\left(^{* *}\right)$ & $-.364\left(^{* *}\right)$ & $.350\left(^{* *}\right)$ & $-.355\left(^{* *}\right)$ & $.374\left(^{* *}\right)$ \\
\hline $\begin{array}{l}\text { Post combined } \\
\text { morphology }\end{array}$ & $.276\left(^{*}\right)$ & $.396\left(^{* *}\right)$ & $-.411\left(^{* *}\right)$ & $.383\left(^{* *}\right)$ & $-.373\left(^{* *}\right)$ & $.373\left(^{* *}\right)$ & $-.361\left(^{* *}\right)$ & $.422\left({ }^{* *}\right)$ \\
\hline
\end{tabular}


Table 6. Correlations between reading and spelling tests conducted in grade A.

\begin{tabular}{|c|c|c|c|c|c|c|c|c|}
\hline & $\begin{array}{l}\text { Word } \\
\text { recognition }\end{array}$ & $\begin{array}{l}\text { Syllable } \\
\text { reading }\end{array}$ & $\begin{array}{c}\text { Syllable } \\
\text { reading time }\end{array}$ & $\begin{array}{l}\text { Pseudo } \\
\text { reading }\end{array}$ & $\begin{array}{l}\text { Pseudo } \\
\text { reading time }\end{array}$ & Word reading & $\begin{array}{l}\text { Words reading } \\
\text { time }\end{array}$ & Spelling \\
\hline Word recognition & & $.229\left(^{*}\right)$ & $-.384\left(^{* *}\right)$ & $.357\left(^{* *}\right)$ & $-.305\left(^{* *}\right)$ & $.283\left({ }^{*}\right)$ & $-.348\left(^{* *}\right)$ & $.455\left(^{(* *}\right)$ \\
\hline Syllable reading & & & $-.696\left(^{* *}\right)$ & $.731\left(^{* *}\right)$ & $-.668\left(^{* *}\right)$ & $.646\left(^{* *}\right)$ & $-.523\left(^{* *}\right)$ & $.582\left(\left(^{* *}\right)\right.$ \\
\hline $\begin{array}{l}\text { Syllable reading } \\
\text { time }\end{array}$ & & & & $-.738\left(^{* *}\right)$ & $.870\left(^{* *}\right)$ & $-.630\left(^{* *}\right)$ & $.814\left(^{* *}\right)$ & $-.689\left(^{* * *}\right)$ \\
\hline Pseudo reading & & & & & $-.746\left(^{* *}\right)$ & $.733\left(^{* *}\right)$ & $-.643\left(^{* *}\right)$ & $.664\left(^{* *}\right)$ \\
\hline $\begin{array}{c}\text { Pseudo reading } \\
\text { time }\end{array}$ & & & & & & $-.575\left(^{* *}\right)$ & $.898\left(^{* *}\right)$ & $-.681\left({ }^{* *}\right)$ \\
\hline Word reading & & & & & & & $-.517\left(^{* *}\right)$ & $.527\left(^{* *}\right)$ \\
\hline $\begin{array}{l}\text { Words reading } \\
\text { time }\end{array}$ & & & & & & & & $-.622\left(^{* *}\right)$ \\
\hline Spelling & & & & & & & & \\
\hline
\end{tabular}

\section{Discussion}

The current study investigated the effect of morphological and phonological intervention programs in kindergarten on the development of reading abilities in $1^{\text {st }}$ grade for Arab speaking children. Three questions were addressed in this research: first, whether a phonological awareness training program can improve phonological awareness abilities; second, whether a morphological awareness training program could enhance morphological awareness abilities, third, whether one or both training programs may help to improve reading abilities in the first grade in comparison to a no-intervention control group.

The results showed that the phonological intervention group was improved in a number of phonological tasks including the last phoneme match task and the phoneme count, as well as in morphological tasks, including the morphological synthesis tests, and the combined morphological score. The morphological intervention group improved in tests of morphological synthesis, morphological analysis and in the combined morphological score, but also in phonological awareness tasks such as the first phoneme match task, the last phoneme match task, the combined phonological score. The morphological training group significantly improved also in the naming test, specifically making fewer naming errors, while improving their reaction time as well. On the other hand, the only task, in which the children of the no intervention control group showed improvement between the initial and the second testing sessions, was the naming task, in which these children improved in their response speed while making significantly more naming errors in the second test session. This improvement in speed, therefore, can be ascribed to a speed accuracy trade-off. Altogether, these results show that both intervention groups (but not the control group) improved substantially across the intervention period. Moreover, the results demonstrate that both intervention programs improved morphological awareness abilities as well as phonological awareness abilities in kindergarten children.

The results of the reading and spelling tests administered to the participants of the three groups in the first grade showed that the two intervention groups had at least some advantage over the control group in measures of fluency in the syllable reading, pseudo word reading and word reading. But, those differences were not statistically significant. Surprisingly, there was a gender effect, with the boys (males) in both intervention groups improving significantly in the pseudo word reading fluency test as compared to the control group. Girls, however, showed no significant differences between the intervention groups and the control group in reading measures. A gender effect was also found in the spelling test, administered in $1^{\text {st }}$ grade with the males of both intervention groups performing better than the control group. However a pair wise comparison between the study groups showed no significant differences between the study groups. In both these tasks there was some superiority for the boys in the morphological intervention group, compared to the other groups, but this was not statistically significant.

The results of this research find that phonological awareness intervention program improves phonological awareness, specifically in two measures: the last phoneme match and phoneme count. These findings are in line with previous results (for example, Ball \& Blachman, 1988; Blachman et al., 1994; Olfsson \& Lundberg, 1983; Brennan \& Ireson, 1997; Kerstholt, Van Bon, \& Schereuder, 1997; Gustafson, Ferreira, \& Ronnberg, 2007). The other intervention group, morphological intervention, showed a similar pattern of results. The morphological 
awareness intervention program improved morphological awareness skills, in comparison to a no-intervention control group. These findings are not surprising, as they are in line with previous studies (for example, Arnbak \& Elbro, 2000; Lyster, 2002). The finding of significant gains in both phonological and morphological tasks after both intervention groups, following the phonological and the morphological training, are also in line with the results reported by Lyster (2002) and Carlisle (1995), explaining that the development of phonological and morphological awareness may be reciprocal. The ability to manipulate the sound structure of words might have facilitated the development of morphological awareness, and the manipulation of the morphological structure of words might have facilitated phonological awareness. Thus, awareness of word structure at both the level of phoneme and morpheme is related to reading acquisition.

An overview of the results of post tests obtained in the current study shows that the morphological awareness training program enhanced those metalinguistic abilities to a greater extent than the phonological awareness training program. This may reflect the nature of the Arabic language. The Arabic language, as other Semitic languages like Hebrew, is thought to be both morphologically rich and morphologically complex. Furthermore, as mentioned in the introduction, the Arabic language is composed of two basic morphemes: the root morpheme usually a compound of three consonants, and various patterns that are superimposed upon the root morpheme. This way a root morpheme of $/ \mathrm{ktb} /$ could be the word / kataba/ (write), by implying the pattern of vowels and consonants specified by the word pattern. This specific characteristic of the Arabic language points to the leading role of morphology in the structure of the language. Given that the morphological structure of the language should affect the way it is stored on the mental lexicon, Arabic is a morphology dominated language (Eviatar \& Ibrahim, 2004; Ibrahim, 2006). A similar notion was suggested for the Hebrew language (Deutsch et al., 1998; Frost, Forster, \& Deutsch, 1997). Thus, the orthography of a given language should affect the way it is learned-especially, how reading would be best acquired. McBride-Chang et al. (2005) developed this idea by investigating how phonological awareness and morphological awareness are associated with word recognition in different scripts among second graders. They critically address the emphasis put on the importance of phonological awareness for early reading in current textbooks of reading development. McBride-Chang et al. (2005) suggest that the extent to which phonological awareness is associated with reading development likely depends on the language in which it occurs and the script to which it is linked as well as the developmental level of the child. Consequently, they examined the strength of the association of phonological awareness with word recognition in four cultures: two in which phonological awareness may be of relatively limited utility for word recognition in primary school (Hong Kong and China), and two in which phonological awareness appears to be relatively important (United States and Korea). This choice reflected the fact that while English is phonology dependent Chinese is not, and vice versa, Chinese is morphology dependent while English is not. Korean is both phonology and morphology dependent. McBride-Chang et al. (2005) also explored the importance of early morphological structure awareness for reading development. The study referred to the premise that although both phonological and morphological awareness are important to reading development, the usefulness of such information depends on the characteristics of the script to be read. McBride-Chang et al. (2005) provide evidence in support of the notion that phonological awareness may be more important for reading in English and Korean than for reading in Chinese. In contrast, morphological awareness may be more important for reading in Chinese and Korean than for reading in English at second grade level. Such findings may suggest that morphological awareness training program might be more useful for reading development in Arabic morphological language. In the current study, only the phonological group was improved in the phoneme count test. This pattern of results was also found by Lyster (2002) implying that only explicit teaching (of how to segment phonemes) may enhance the children's ability to segment phonemes in a given word. One should note however, that in the current study, the results in this test should be cautiously interpreted, because most of the children could not perform this test even after the intervention.

The results showed that all three groups improved in the general ability tests, specifically in the Peabody, Raven and Verbal memory tests, although the improvement of the control group in the latter test was only marginally significant. Those results were predictable, and reflect the normal cognitive development and growth during the period of research, namely in kindergarten.

Rather odd results on the object naming test were found (RAN test). However, taking into account both the accuracy (number of errors) and fluency (time measure) may shed light on the overall behaviour of the three groups. Namely, the control group got faster yet committed more errors. The phonological group did not change over time, while the morphological group improved significantly, both in reducing their reaction time (margin- 
ally significant improvement) and in reducing the number of the errors committed. Naming ability as tested in the RAN can be related to reading fluency (for example, Plaza \& Cohen, 2003). But, no corresponding differences in reading fluency were found in the current study. In order to exclude an overlap between the name of objects in the naming test and the items that were given in the two intervention programs, simple examination of those items was undertaken. It was found that the word /ketab/ (book) was part of the examples given to the morphological intervention program. However, the word /korsi/ (chair) was part of the items used as an example for one or more of the phonological intervention sessions. This examination of the items suggests that specific items of the morphological intervention program could not have contributed to making it easier for the children to recall the items from long term memory as a result of the intervention program. If this was the case, then we would have expected that the children in the phonological intervention group enhance their naming ability as well. However, the performance of this group did not improve compared to the control group.

\section{Reading Abilities}

The current results showed that, unfortunately, there were no significant differences between groups in the performance of the reading tests in the $1^{\text {st }}$ grade. This finding is rather surprising since previous studies found that phonological intervention programs in kindergarten do enhance reading abilities in $1^{\text {st }}$ graders (for example, Brennan \& Ireson, 1997; Ball \& Blachman, 1988; Blachman et al., 1994). No published studies, known to the authors, reported that phonological or morphological training did not enhance reading or spelling abilities. This may reflect either the fact that enhancement was found in all studies or that studies wherein failures to record the expected enhancement were not published.

The failure to enhance reading measures in both the phonological and the morphological intervention groups in the current study may therefore reflect several possibilities. First, assuming that others have found similar results, in languages other than Arabic, but abstained from publishing them, the current results may be in line with studies in other languages. Second, the failure to attain reading enhancement in both programs may relate to the complex nature of the development of reading skills in Arabic. The diglossia issue in the Arabic language can be one of the reasons for the complexity of learning to read in Arabic. Children are mainly exposed to the spoken Arabic language before $1^{\text {st }}$ grade, and thus encounter the literary Arabic firstly in the beginning of the first grade. The literary Arabic found to be a second language (for example, Eviatar \& Ibrahim, 2004; Ibrahim \& AharonPeretz, 2005), and hence making it difficult to learn to read and write. Another complexity found in the orthography of the literary Arabic language introduced by Ibrahim, Eviatar, \& Aharon-Peretz (2002) emphasizes the complexity of the Arabic orthography, which compared processing time in Arabic (their $1^{\text {st }}$ language) and Hebrew (their $2^{\text {nd }}$ language). The results show that Arabic language processing is slower than Hebrew. This is due to the complex orthography of Arabic shown in appendix I. Due to this complexity, the reading instruction curriculum for Arabic first language speakers is built in a very structured and slow way. Because of this, only by the end of the $1^{\text {st }}$ grade school year Arab students learn reading all the Arabic letters and vowels. Evidence for this is the most popular text book for reading instruction in the first grade (Al Rae'd, 1991). This book uses some of the letters in words only very close to the end, which mostly instructed at the end of the school year. Another point can be made based on a personal communication (Mrs. Hanan Besharat who teaches in the school in which the study taken part) reporting that part of the words could be difficult for the children to read since it include letters that they have not learned yet. In this manner, most children, by the middle of first grade, have not yet reached proficiency in reading. This may the reason for the large between-participants' differences found in the present study, as was the case in the fluency measures of syllable reading, pseudo words reading, and word reading. Most of the differences that have been found might be explained by intra-personal variance, and not by variance resulting from the intervention programs a year before. Therefore, further investigations of reading abilities need to be administered for the same children in a later stage, such as the end of second grade, or even in the middle of third grade. By then children should have mastered reading, and thus it can be assumed that variances between children within each group will have become smaller, and thus the differences between groups will become apparent.

A rather unexpected finding of the current study which was not included in the research aims and hypotheses was the finding of gender differences in the effects of the intervention programs. Gender differences were found in two reading tests: the pseudo word reading fluency test and the spelling test. Further analysis of those tests showed that in the pseudo word reading fluency $1^{\text {st }}$ grade males who a year earlier participated in the phonolog- 
ical and the morphological intervention programs showed a marginally significant improvement compared to the control group. No such differential enhancement was found for the corresponding females. A similar gender effect was found also in the spelling test wherein a significant enhancement was found for the males only of both intervention groups versus the control group. However, the post hoc test did not find any differences between any pair of study groups. One study (Olofsson \& Lundberg, 1993) reported sex differences in the effects of training phonological awareness in kindergarten. This study involved three experimental groups and two control groups. The training programs were 6 - 8 weeks long (similar to the programs in the current study). It was found that boys showed higher variability and slightly lower means than girls. Moreover, boys were the majority among the children who achieved below half of the items correct on the phonological analysis and synthesis in the pre tests as well as the post intervention tests. Olofsson \& Lundberg (1993) did not try to explain these results. Recently, Taha (2006) studied gender differences that were found in cognitive abilities, in a specific modality-spelling accuracy, in the Arabic language for 288 Arabic speaking students from grade 1 to grade 9. Girls made fewer spelling errors across all ages, especially errors of phonological nature. The results of the study indicated that girls are better at phonology than boys, and thus girls might be better equipped with decoding and verbal abilities than boys, abilities that are strongly related to reading and spelling development. Taha's (2006) results may explain some of results of the current study. In the current study, girls, in all three groups, seemed to be better in reading and writing, especially in the tasks of pseudo word reading fluency and spelling. Thus, it may be the case that girls may develop spelling and phonological abilities without the need for specific interventions at kindergarten level. However, the boys may benefit from such an intervention because the everyday school experience may not suffice for them to attain levels of proficiency as the girls. If true, the current results, therefore, indicate a possible role for metalinguistic interventions in males but less so in females.

Sex differences in performance have been observed in a wide range of tasks involving language (Kimura, 2002; Halpern, 2004). In most but not all of these tasks women tend to outperform men. Women have been found to show better performance than men in episodic memory tasks (remembering a given set of stimuli) for a wide range of verbal item types, including words, digits and paragraph content. Women have also shown superior performance at episodic memory tasks involving nameable items such as landmarks and real objects. The general female advantage at language-related tasks appears to begin in quite early age (Ullman, Miranda, \& Travers, in press). The apparent female advantage at many language-related tasks has led to the widely-accepted hypothesis that females have an advantage over males in processing verbal information (Kimura, 1999). Females' superior memory for non-verbal stimuli, such as faces and objects, and their reliance on landmarks during spatial navigation tasks, may reflect their ability to internally verbalize these stimuli (Ullman et al., in press).

A recently proposed explanatory account of neurocognitive sex differences in language and memory posits that females tend to have an advantage over males at storing and/or retrieving knowledge in the declarative memory brain system, which underlies the storage and use of knowledge of facts and events (Ullman et al., 2002; Ullman, 2004). Some evidence indicates that estrogens affect declarative memory (Ullman et al., 2002). This study has shown that estrogens enhanced the ability to produce regular past tenses for women, but decreased it in men. On the other hand, men were found to be better in the procedural memory, which supports the learning and execution of motor and cognitive skills, especially those involving sequences-like mental grammar.

The current results may perhaps indirectly reflect a male advantage in procedural learning. In order to trigger long-lasting performance gains on a given task a critical number of practices are needed within each training session (Hauptmann \& Karni, 2002; Hauptmann, Reinhart, Brandt, \& Karni, 2005). Both boys and girls in our study had a similar amount of training in each session on either phonological awareness skills, or morphological awareness skills. Two ways are available to explain the differential effects of the interventions in boys versus girls. One, that because language related skills are involved the females attain optimal gains in performance even by means of every day life experience. However, it may be the case that the boys are better able to attain skilled performance than the girls within the sessions (despite their lower starting points, given the female advantage in language) because the limited amount of practice available in the intervention programs sufficed for some of the boys to acquire phonological abilities from the training relative to the boys who did not train (control). The amount of practice afforded was however, insufficient to help the girls, and so the intervention groups were not superior to the control group.

Some methodological issues should be addressed while dealing with the study results. As noted in the methods section, most of the tests were designed for the special needs of the current study. Those tests have not been validated prior to the current research, although post hoc, a relatively good reliability was found for most of the tests. The intervention programs were chosen also to accord with the literature both in Hebrew (Adams et 
al., 2001) and Danish (Lyster, 2002). The post intervention test results show that the intervention programs did enhance phonological and morphological awareness in a similar way that Lyster's (2002) study in Danish had affected.

Second issue, there was a small number of participants in comparison to the number of variables tested. This might be one of the reasons why no significant differences between experimental groups were found in reading ability measures. This also made regression analysis difficult to implement. The numbers of children in each gender did not match, the distribution of children in the school, calling for caution in interpreting the findings of gender differences.

Some other methodological issues relate to the setting in which the research was conducted. For logistical problems, the pre-tests, post-tests and the intervention programs in kindergarten were administered in the class setting, were other children play, or study the regular curriculum. This setting might have intervened with the ability of the researchers to administer the tests, and with the ability of children to stay focused on the tasks during the tests as well as during the interventions. For the same reasons, and for lack of resources, the number of children when teaching the training programs was ten on average, while most of the intervention studies mentioned in this paper used small groups (three to five children in each group) in their intervention (see for example, Arnbak \& Elbro, 2000; Ball \& Blachman, 1988; Blachman et al., 1994; Lyster, 2002).

\section{Summary}

In summary, this study tentatively provides two conclusions. First, concerning the type of training that would be expected to enhance reading and spelling abilities in $1^{\text {st }}$ graders. This study, and others (i.e., Carlisle, 1995; Lyster, 2002), found that morphological training had better effects on metalinguistic abilities (phonological and morphological awareness). McBride-Chang et al. (2005) found that the type of training should be determined in relation to the language studied. If the language was basically morphological, like Arabic in the current study and the Chinese in the former study, a morphological training program may be superior in enhancing reading abilities. This leads to the conclusion that in order to enhance reading in Arabic language, a morphological awareness training program would be more effective. Additional research on this point could reinforce this proposal. The second point concerns gender differences in the context of reading proficiency and its acquisition. The very preliminary results of the current study are in line with the general proposal that as a result of biological and/or social factors, females practice verbal abilities more than males. Therefore, females may reach proficiency in reading without any additional training. Males, on the other hand, may need training program in order to improve their metalinguistic abilities. Thus, overall, training programs may help to improve reading ability, especially for males. Further research could clarify these issues.

\section{References}

Abu-Rabia, S. (1997a). Reading in Arabic Orthography: The Effect of Vowels and Context on Reading Accuracy of Poor and Skilled Native Arabic Readers in Reading Paragraphs, Sentences, and Isolated Words. Journal of Psycholinguistic Research, 26, 465-482. http://dx.doi.org/10.1023/A:1025034220924

Abu-Rabia, S. (1997b). Reading in Arabic Orthography: The Effect of Vowels and Context on Reading Accuracy of Poor and Skilled Native Arabic Readers. Reading and Writing: An Interdisciplinary Journal, 9, 65-78. http://dx.doi.org/10.1023/A:1007962408827

Abu-Rabia, S. (1997c). The Need for Cross-Cultural Considerations in Reading Theory: The Effects of Arabic Sentence Context in Skilled and Poor Readers. Journal of Research in Reading, 20, 137-147.

http://dx.doi.org/10.1111/1467-9817.00026

Abu-Rabia, S. (2001). The Role of Vowels in Reading Semitic Scripts Data from Arabic and Hebrew. Reading and Writing: An Interdisciplinary Journal, 14, 39-59. http://dx.doi.org/10.1023/A:1008147606320

Abu-Rabia, S. (2002). Reading in a Root-Based-Morphology Language: The Case of Arabic. Journal of Research in Reading, 25, 299-309. http://dx.doi.org/10.1111/1467-9817.00177

Abu-Rabia, S., \& Siegel, L. S. (1995). Different Orthographies Different Context Effects: The Effects of Arabic Sentence Context in Skilled and Poor Readers. Reading Psychology: An International Quarterly, 16, 1-19. http://dx.doi.org/10.1080/0270271950160101

Abu-Rabia, S., Share, D., \& Mansour, M. S. (2003). Word Recognition and Basic Cognitive Processes among Reading Disabled and Normal Readers in Arabic. Reading and Writing: An Interdisciplinary Journal, 16, 423-442.

http://dx.doi.org/10.1023/A:1024237415143 
Adams, M. J., Foorman, B., Lundberg, I., \& Beeler, T. (2001). Phonemic Awareness in Young Children: A Classroom Curriculum. Baltimore, MD: P.H. Brookes.

Arnbak, E., \& Elbro, C. (2000). The Effects of Morphological Awareness Training on the Reading and Spelling Skills of Young Dyslexics. Scandinavian Journal of Educational Research, 44, 229-251. http://dx.doi.org/10.1080/00313830050154485

Ball, E. W. (1993). Phonological Awareness: What's Important and to Whom? Reading and Writing: An Interdisciplinary Journal, 5, 141-159. http://dx.doi.org/10.1007/BF01027481

Ball, E. W., \& Blachman, B. A. (1988). Phoneme Segmentation Training: Effect on Reading Readiness. Annals of Dyslexia, 38, 208-225. http://dx.doi.org/10.1007/BF02648257

Bentin, S., \& Feldman, L. B. (1990). The Contribution of Morphological and Semantic Relatedness to Repetition Priming at Short and Long Lags: Evidence from Hebrew. The Quarterly Journal of Experimental Psychology Section A, 42, 693-711. http://dx.doi.org/10.1080/14640749008401245

Berent, I. (2002). Identity Avoidance in the Hebrew Lexicon: Implications for Symbolic Accounts of Word Formation. Brain and Language, 81, 326-341. http://dx.doi.org/10.1006/brln.2001.2528

Berent, I., \& Shimron, J. (1997). The Representation of Hebrew Words: Evidence from the Obligatory Contour Principle. Cognition, 64, 39-72. http://dx.doi.org/10.1016/S0010-0277(97)00016-4

Blachman, B. A., Ball, E., Black, R. S., \& Tangel, D. M. (1994). Kindergarten Teachers Develop Phoneme Awareness in Low-Income, Inner-City Classrooms: Does It Make a Difference? Reading and Writing: An Interdisciplinary Journal, 6, 1-18. http://dx.doi.org/10.1007/BF01027275

Bowey, J. A., \& Francis, J. (1991). Phonological Analysis as a Function of Age and Exposure to Reading Instruction. Applied Psycholinguistics, 12, 91-121. http://dx.doi.org/10.1017/S0142716400009395

Bradley, L., \& Bryant, P. E. (1983). Categorizing Sounds and Learning to Read-A Causal Connection. Nature, 301, 419421. http://dx.doi.org/10.1038/301419a0

Brennan, F., \& Ireson, J. (1997). Training Phonological Awareness: A Study to Evaluate the Effects of a Program of Metalinguistic Games in Kindergarten. Reading and Writing: An Interdisciplinary Journal, 9, 241-263. http://dx.doi.org/10.1023/A:1007979321948

Brittain, M. M. (1970). Inflection Performance and Early Reading Achievement. Reading Research Quarterly, 6, $34-48$. http://dx.doi.org/10.2307/747047

Bryant, P., \& Bradley, L. (1985). Children’s Reading Problems. Oxford: Blackwell.

Carlisle, J. (1995). Morphological Awareness and Early Reading Achievement. In L. B. Feldman (Ed.), Morphological Aspects of Language Processing (pp. 189-209). Hilsdale, NJ: Lawrence Erlbaum Associates.

Carlisle, J. F. (1987). The Use of Morphological Knowledge in Spelling Derived Forms by Learning Disabled and Normal Students. Annals of Dyslexia, 37, 90-108. http://dx.doi.org/10.1007/BF02648061

Casalis, S., \& Louis-Alexandre, M. F. (2000). Morphological Analysis, Phonological Analysis and Learning to Read French: A Longitudinal Study. Reading and Writing: An Interdisciplinary Journal, 12, 303-335. http://dx.doi.org/10.1023/A:1008177205648

Clin, E., Wade-Woolley, L., \& Heggie, L. (2009). Prosodic Sensitivity and Morphological Awareness in Children’s Reading. Journal of Experimental Child Psycholology, 104, 197-213. http://dx.doi.org/10.1016/j.jecp.2009.05.005

Denckla, M. B., \& Rudel, R. G. (1976). Naming of Object-Drawings by Dyslexic and Other Learning Disabled Children. Brain and Language, 3, 1-15. http://dx.doi.org/10.1016/0093-934X(76)90001-8

Dunn, L. M., \& Dunn, L. M. (1981). Peabody Picture Vocabulary Test-Revised. Circle Pines, MN: American Guidance Service, Inc.

Elbro, C., \& Arnbak, E. (1996). The Role of Morpheme Recognition and Morphological Awareness in Dyslexia. Annals of Dyslexia, 46, 209-240. http://dx.doi.org/10.1007/BF02648177

Eviatar, Z., \& Ibrahim, R. (2001). Bilingual Is as Bilingual Does: Metalinguistic Abilities of Arabic-Speaking Children. Applied Psycholinguistics, 21, 451-471. http://dx.doi.org/10.1017/S0142716400004021

Eviatar, Z., \& Ibrahim, R. (2004). Morphological and Orthographic Effects on Hemispheric Processing of Nonwords: A Cross-Linguistic Comparison. Reading and Writing: An Interdisciplinary Journal, 17, 691-705. http://dx.doi.org/10.1007/s11145-004-2659-8

Farid, M., \& Grainger, J. (1996). How Initial Fixation Position Influences Visual Word Recognition: A Comparison of French and Arabic. Brain and Language, 53, 351-361. http://dx.doi.org/10.1006/brln.1996.0053

Ferguson, C. A. (1959). Diglossia. Word, 14, 47-56.

Fischer, F. W., Shankweiler, D., \& Liberman, I. Y. (1985). Spelling Proficiency and Sensitivity to Word Structure. Journal 
of Memory and Language, 24, 423-441. http://dx.doi.org/10.1016/0749-596X(85)90038-5

Fowler, A. E., \& Liberman I. Y. (1995). The Role of Phonology and Orthography in Morphological Awareness. In L. B. Feldman (Ed.), Morphological Aspects of Language Processing (pp. 157-188). Hillsdale, NJ: Lawrence Erlbaum.

Frost, R., \& Bentin, S. (1992). Processing Phonological and Semantic Ambiguity: Evidence from Semantic Priming at Different SOAs. Journal of Experimental Psychology: Learning, Memory and Cognition, 18, 58-68. http://dx.doi.org/10.1037/0278-7393.18.1.58

Frost, R., Forster, K. I., \& Deutsch, A. (1997). What Can We Learn from the Morphology of Hebrew? A Masked Priming Investigation of Morphological Representation. Journal of Experimental Psychology: Learning, Memory, and Cognition, 23, 829-856. http://dx.doi.org/10.1037/0278-7393.23.4.829

Geva, E., Wade-Wooley, L., \& Shany, M. (1997). Development of Reading Efficiency in First and Second Language. Scientific Studies of Reading, 1, 119-144. http://dx.doi.org/10.1207/s1532799xssr0102_2

Gustafson, S., Ferreira, J., \& Rönnberg, J. (2007). Phonological or Orthographic Training for Children with Phonological or Orthographic Decoding Deficits. Dyslexia, 13, 211-229. http://dx.doi.org/10.1002/dys.339

Halpern, D. F. (2004). A Cognitive-Process Taxonomy for Sex Differences in Cognitive Abilities. Current Directions in Psychological Science, 13, 135-139. http://dx.doi.org/10.1111/j.0963-7214.2004.00292.x

Hauptmann, B., \& Karni, A. (2002). From Primed to Learn: The Saturation of Repetition Priming and the Induction of LongTerm Memory. Cognitive Brain Research, 13, 313-322. http://dx.doi.org/10.1016/S0926-6410(01)00124-0

Hauptmann, B., Reinhart, E., Brandt, S. A., \& Karni, A. (2005). The Predictive Value of the Leveling off of within Session Performance for Procedural Memory Consolidation. Cognitive Brain Research, 24, 181-189. http://dx.doi.org/10.1016/j.cogbrainres.2005.01.012

Ibrahim, R. (2006). Morpho-Phonemic Similarity within and between Languages: A Factor to Be Considered in Processing Arabic and Hebrew. Reading and Writing, 19, 563-586. http://dx.doi.org/10.1007/s11145-006-9009-y

Ibrahim, R. (2009). The Cognitive Basis of Diglossia in Arabic: Evidence from a Repetition Priming Study within and between Languages. Psychology Research and Behavior Management, 2009, 93-105. http://dx.doi.org/10.2147/PRBM.S5138

Ibrahim, R., \& Aharon-Peretz, J. (2005). Is Literary Arabic a Second Language for Native Arabic Speakers? Evidence from Semantic Priming Study. Journal of Psycholinguistic Research, 34, 51-70. http://dx.doi.org/10.1007/s10936-005-3631-8

Ibrahim, R., Eviatar, Z., \& Aharon-Peretz, J. (2002). The Characteristics of Arabic Orthography Slow Its Processing. Neuropsychology, 16, 322-326. http://dx.doi.org/10.1037/0894-4105.16.3.322

Kerstholt, M., Van Bon, W. H. J., \& Schreuder, R. (1997). Using Visual Support in Preschool Phonemic Segmentation Training. Reading and Writing, 9, 265-283. http://dx.doi.org/10.1023/A:1007910714062

Kimura, D. (2002). Sex Differences in the Brain. Scientific American Mind, 12, 32-37.

Kimura, D. (1999). Sex and Cognition. Cambridge: The MIT Press.

Landerl, K., \& Wimmer, H. (2000). Deficits in Phoneme Segmentation Are Not the Core Problem of Dyslexia: Evidence from German and English Children. Applied Psycholinguistics, 21, 243-262.

http://dx.doi.org/10.1017/S0142716400002058

Lyster, S. A. H. (2002). The Effects of Morphological vs Phonological Awareness Training in Kindergarten on Reading Development. Reading and Writing: An Interdisciplinary Journal, 15, 261-294. http://dx.doi.org/10.1023/A:1015272516220

Mann, V. (1998). Language Problems: A Key to Early Reading Problems. In B. Wong (Ed.), Learning about Learning Disabilities (pp. 163-193). San Diego, CA: Academic Press.

Mann, V. A., \& Liberman, I. Y. (1984). Phonological Awareness and Verbal Short-Term Memory. Journal of Learning Disabilities, 17, 592-599. http://dx.doi.org/10.1177/002221948401701005

Mcbride-Chang, C., Cho, J.-R., Liu, H. Y., Wagner, R. K., Shu, H., Zhou, A., Cheuk, C., \& Muse, A. (2005). Changing Models across Cultures: Associations of Phonological Awareness and Morphological Structure Awareness with Vocabulary and Word Recognition in Second Graders from Beijing, Hong Kong, Korea, and the United States. Journal of Experimental Child Psychology, 92, 140-160. http://dx.doi.org/10.1016/j.jecp.2005.03.009

Nunes, T., Bryant, P., \& Bindman, M. (1997). Morphological Spelling Strategies: Developmental Stages and Processes. Developmental Psychology, 33, 637-649. http://dx.doi.org/10.1037/0012-1649.33.4.637

Plaza, M., \& Cohen, H. (2003). The Interaction between Phonological Processing, Syntactic Awareness, and Naming Speed in the Reading and Spelling Performance of First-Grade Children. Brain and Cognition, 53, 287-292.

http://dx.doi.org/10.1016/S0278-2626(03)00128-3

Rubin, H. (1991). Morphological Knowledge and Writing Ability. In R. M. Joshi (Ed.), Writing Language Disorders (pp. 43-69). Boston, MA: Kluwer Academic. http://dx.doi.org/10.1007/978-94-011-3732-4_3 
Saiegh-Haddad, E. (2003). Linguistic Distance and Initial Reading Acquisition: The Case of Arabic Diglossia. Applied Psycholinguistics, 24, 431-451. http://dx.doi.org/10.1017/S0142716403000225

Saiegh-Haddad, E. (2004). The Impact of Phonemic and Lexical Distance on the Phonological Analysis of Words and Pseudo Words in a Diglossic Context. Applied Psycholinguistics, 25, 495-512. http://dx.doi.org/10.1017/S0142716404001249

Shany, M., Zieger, T., \& Ravid, D. (2001). The Development and Validation of Assessment Tools for Basic Reading and Writing Processes: Findings on the Functioning of Normal Readers in Different Grades and Applications for Evaluation Processes in Readers with Difficulties. Script: Literacy Research, Theory and Practice, 2, 167-203.

Shatil, E. (2002). Hebrew Battery. “Ach” Press, Ltd.

Stanovich, K. E. (1986). Matthew Effects in Reading: Some Consequences of Individual Differences in the Acquisition of Literacy. Reading Research Quarterly, 21, 360-406. http://dx.doi.org/10.1598/RRQ.21.4.1

Stanovich, K. E., \& West, R. (1989). Exposure to Print and Orthographic Processing. Reading and Research Quarterly, 24, 402-433. http://dx.doi.org/10.2307/747605

Taha, H. (2006). Females’ Superiority on Phonological and Lexical Processing. The Reading Matrix, 6, 70-79.

Torneus, M. (1987). The Importance of Metaphonological and Metamorphological Abilities for Different Phases of Reading Development. Paper Presented at the Third Word Congress of Dyslexia, Crete.

Tunmer, W. E., \& Bowey, J. (1984). Metalinguistic Awareness and Reading Acquisition. In W. E. Tunmer, C. Pratt, \& M. L. Herriman (Eds.), Metalinguistic Awareness in Children: Theory, Research and Implications (pp. 144-168). Berlin: Springer-Verlag.

Ullman, M. T. (2004). Contribution of Memory Circuits to Language: The Declarative/Procedural Model. Cognition, 92, 231-270. http://dx.doi.org/10.1016/j.cognition.2003.10.008

Ullman, M. T., Estabrooke, I., Steinhauer, K., Brovetto, C., Pancheva, R., Ozawa, K., Mordecai, K., \& Maki, P. (2002). Sex Differences in the Neurocognition of Language. Brain and Language, 83, 141-143.

Ullman, M. T., Miranda, R. A., \& Travers, M. (in press). Sex Differences in the Neurocognition of Language. In J. B. Becker, K. J. Berkley, N. Geary, E. Hampson, J. Herman, \& E. Young (Eds.), Sex on the Brain: From Genes to Behavior. New York: Oxford University Press.

Wagner, R. K., \& Torgesen, J. K. (1987). The Nature of Phonological Processing and Its Causal Role in the Acquisition of Reading Skills. Psychological Bulletin, 101, 192-212. http://dx.doi.org/10.1037/0033-2909.101.2.192

Wolter, J. A., Wood, A., \& D’Zatko, K. W. (2009). The Influence of Morphological Awareness on the Literacy Development of First-Grade Children. Language, Speech, and Hearing Services in Schools, 40, 286-298.

http://dx.doi.org/10.1044/0161-1461(2009/08-0001)

Zaaiman, H., Van Der Filer, H., \& Thijs, G. D. (2001). Dynamic Testing in Selection for an Educational Programme: Assessing South African Performance on the Raven Progressive Matrices. International Journal of Selection and Assessment, 9, 258-269. http://dx.doi.org/10.1111/1468-2389.00178 